\title{
NOVEDADES SOBRE LA CONSTRUCCIÓN DEL FORO \\ DE LIBISOSA: NOTICIA PRELIMINAR DE LAS ÚLTIMAS INTERVENCIONES ARQUEOLÓGICAS
}

\section{NEW INFORMATION ON THE CONSTRUCTION OF THE FORUM OF LIBISOSA: A FIRST ANNOUNCEMENT ON THE LATEST ARCHAEOLOGICAL CAMPAIGNS}

\author{
HÉCTOR UROZ RODRÍGUEZ \\ Universidad de Murcia \\ Murcia, España \\ hector.uroz@um.es \\ JosÉ UROZ SÁEZ \\ Universidad de Alicante \\ Alicante, España \\ jose.uroz@hotmail.com
}

Cómo citar este artículo: Uroz Rodríguez, H.; Uroz Sáez, J. (2021). Novedades sobre la construcción del foro de Libisosa: noticia preliminar de las últimas intervenciones arqueológicas. Al-Basit (66), 207-246. http://doi.org/10.37927/albasit.66_5

Recibido/Received: 22-04-2021

Aceptado/Accepted: 12-08-2021

RESUMEN: El presente trabajo constituye un pequeño avance de los resultados de las intervenciones arqueológicas llevadas a cabo en las campañas de 2019 y 2020 en el sector norte del foro romano de Libisosa (Lezuza), como esfuerzo coordinado con su puesta en valor. Se trata, concretamente, de la excavación practicada en el ambiente 196, el espacio existente bajo el pórtico norte en su conexión con el perímetro sur del granero, que testifica la existencia de un gran relleno sincrónico,
ABSTRACT: The following paper offers a small preview of the results of the archaeological studies carried out in the 2019 and 2020 campaigns in the Northern sector of the Roman forum of $\mathrm{Li}$ bisosa (Lezuza, Albacete, Spain), a coordinated effort aiming at its consolidation. Specifically, we are referring to the excavation of unit 196, the space to be found beneath the Northern portico in its connection with the Southern perimeter of the granary, which reveals the existence of a contem- 
en el que se ha recuperado una considerable cantidad de registro material cerámico, que ofrece una datación ante quem de época augustea, la fecha fundacional de la colonia. A su vez, se ha podido documentar que la estructura de diferente orientación que originariamente se pensaba que era de la fase I o precolonial, y que delimita el citado ambiente por el sur, formaba parte del diseño originario del foro (fase II), con el objetivo de servir de sostén de la parte septentrional de la plaza, y quitarle presión de la ladera al edificio destinado al almacenaje de grano.

PALABRAS CLAVE: Excavaciones arqueológicas, Lezuza, forum, colonia romana, fundación, Augusto, ius italicum, horreum. porary filling of this space where a considerable amount of pottery was recovered, offering an ante quem dating to the Augustan period, the date in which the colony was founded. It was also possible to record how the structure with the different orientation which also marks the unit's South side, originally thought to belong to the precolonial phase (I), already formed part of the forum's original design (phase II), its function: to support the North section of the plaza, as well as to relieve the granary building from the pressure of the slope.

KEYWORDS: Archaeological excavations, Lezuza, forum, Roman colony, foundation, Augustus, ius italicum, horreum.

\section{INTRODUCCIÓN}

El Proyecto Libisosa se viene desarrollando de forma ininterrumpida desde el año 1996, fecha en la que se iniciaron las excavaciones arqueológicas ${ }^{1}$ en el llamado «Cerro del Castillo» de Le-

\footnotetext{
${ }^{1}$ A lo largo de estos años, las actuaciones han tenido lugar, fundamentalmente, en el marco del programa de excavaciones arqueológicas sistemáticas y proyectos de investigación de la Consejería de Educación y Cultura de Castilla-La Mancha, pero también ha encontrado eco y ayuda en el Ayuntamiento de Lezuza, la Diputación de Albacete/Instituto de Estudios Albacetenses, el INEM-SEPECAM, la Fundación SACAM, y entidades privadas como la Fundación Cajasol, así como las Universidades de Alicante y Murcia. Formó parte igualmente del Proyecto de Investigación del Ministerio de Educación y Ciencia (BHA2002-03795) «Modelos romanos de integración territorial en el sur de Hispania Citerior», así como del Proyecto de la Universidad de Alicante «Ciudad y territorio», bajo la dirección del profesor José Uroz Sáez. Recientemente se ha sumado a la codirección, junto a los arriba firmantes, José Antonio Molina Gómez, de la Universidad de Murcia.
} 
zuza. Ha contado con el firme apoyo de la Diputación de Albacete, sustento que se ha mantenido a través del tiempo (los últimos años mediante el Instituto de Estudios Albacetenses), y que ha sido clave para que fructificara la investigación, y el desarrollo cultural y económico que ha conllevado en esta localidad albaceteña de en torno a un millar de habitantes, cuyo yacimiento contiene restos, como es sabido, que van desde el Bronce Final hasta el período bajomedieval (Fig. 1a).

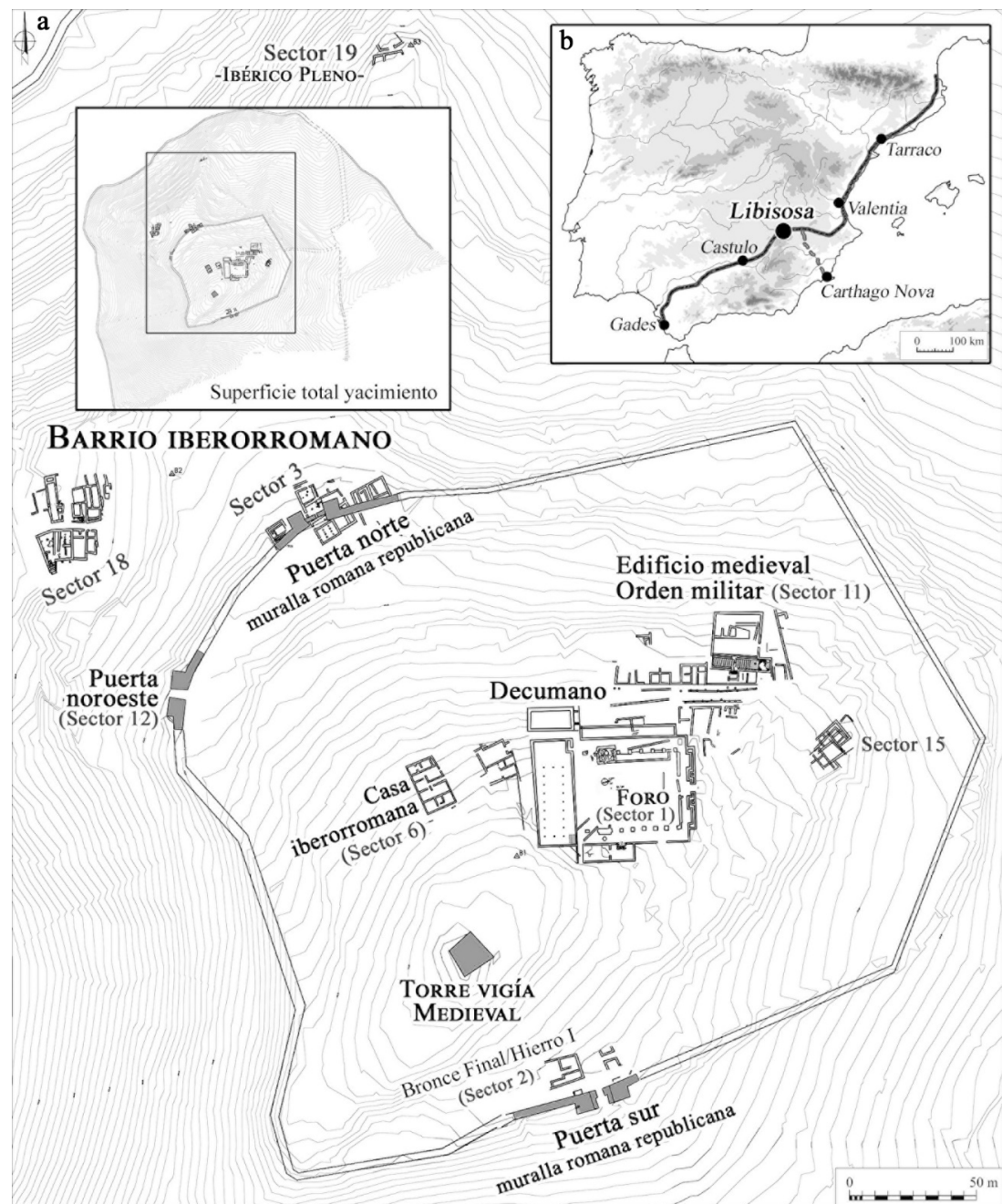

Figura 1. a. Sectores excavados del yacimiento, a partir de levantamiento topográfico de Juan Antonio Tolosa y Jesús Cruz García (Diputación de Albacete) y fotogrametría de José Luis Fuentes (Oppida S.L.); b. situación de Libisosa respecto a la via Heraclea 
Buena parte de la importancia del oppidum ibérico y la ciudad romana de Libisosa se debe a una ubicación geoestratégica privilegia$\mathrm{da}$, nudo de comunicaciones de los caminos ganaderos antiguos, que unían las tierras de la actual Andalucía con Levante, y la Meseta con la costa murciana (Fig. 1b). El eje viario más importante durante las épocas ibérica y romana republicana fue sin duda la llamada via Heraclea (Uroz Sáez y Uroz Rodríguez, 2016; Uroz Sáez y Poveda, 2008, pp. 145-148; Blánquez, 1990) o Camino de Aníbal (Sillières, 1999), recogida en los Vasos de Vicarello (CIL XI, 3281-3284; Roldán Hervás, 1975, pp. 149-160), que describen la ruta a seguir desde Gades a Roma, alguno de cuyos tramos, junto a Lezuza, todavía se conservan. Los posteriores itinerarios (Roldán Hervás, 1975; Sanz, 1989; 20022003), de época imperial (Itinerario de Antonino, 446, 11; Anónimo de Rávena, IV, 44; 313,14), seguirán dejando constancia del valor estratégico de la ciudad, conectada igualmente por otra calzada romana con Carthago Nova (Sillières, 1982). En ambas épocas, el territorio que controlaba era amplísimo, rico en recursos hídricos, en abundantes pastos que propiciaron la existencia de una nutrida cabaña ganadera (favorecida por la existencia de sal en la cercana Pinilla), con extensas masas forestales, que permitieron una suficiente explotación maderera y de la caza, territorio propicio para el cultivo del cereal, en su mayor parte seguramente de secano (Sánchez Sánchez, 1982, I, pp. 32-34, pp. 69-72; Romero Díaz y Ruiz García, 1986). El cultivo de regadío, del que quedan herramientas agrícolas en el oppidum ibérico a modo de testigo, se practicó preferentemente a lo largo del lecho del río Lezuza, dedicado a la horticultura y algunos cereales.

La instalación humana en el yacimiento está documentada desde finales de la Edad del Bronce y del Hierro I/Orientalizante, pero es a partir del siglo V y IV a.C. cuando se desarrollaría el oppidum ibérico, perteneciente a la Oretania según la Geografía de Ptolomeo (II, 6, 58), con suficiente entidad para controlar un amplio territorio (Soria, 2002, p. 138; 2007, p. 243; Uroz Sáez, Poveda y Márquez, 2003, pp. 224-225). De esta etapa quedan huellas en diversas zonas del cerro, fundamentalmente cerámica ática y restos 
de monumentos funerarios, aunque las estructuras habitacionales (con sus materiales dentro) se concentran en el Sector 19, el más septentrional y cercano al río de lo excavado hasta la fecha (Uroz Rodríguez, e. p., pp. 21-34).

Los acontecimientos de la II Guerra Púnica debieron afectar al poblado. No sabemos en qué medida por los agentes cartagineses, pero desde luego por la parte romana desde el año 214 a.C., cuyo control ya no abandonarán (Uroz Sáez, 2012, p. 93). Sin embargo, mientras que la mayor parte de los poblados ibéricos de la zona desaparecen, se consolida y cobra mayor vigor el de Libisosa (Uroz Sáez y Poveda, 2008, p. 155), debido sin duda a su posición estratégica, útil para asegurar el tránsito de las legiones romanas, correos, mercancías, y por su fácil acceso a Carthago Nova, de cuyo hinterland formaba parte. La prueba de ese notable desarrollo iberorromano son los restos de estructuras edilicias y materiales que se hallan por todas las áreas del yacimiento en las que se ha tenido la oportunidad de excavar, especialmente los sectores 3 y 18 (Uroz Rodríguez e. p.; 2020a, con la bibliografía anterior), cuyos materiales evidencian un avanzado grado de auto-romanización (proceso bien explicado por Coarelli, 1996; 2008) de la población indígena (o, al menos, de su élite dirigente), fruto de un prematuro contacto con el agente itálico.

Sin embargo, esa situación quedó traumáticamente interrumpida por las guerras sertorianas, con la destrucción definitiva del oppidum (Uroz Rodríguez y Uroz Sáez, 2014; De Miguel y Uroz Rodríguez, 2017; Uroz Rodríguez, Ribera y Hernández, 2020). El sector 18 ya no se volvió a habitar, y tampoco el sector 3 , sobre el que, además, se asentaría directamente la Puerta Norte de la muralla romana que el ejército romano levantaría apresuradamente abarcando la parte más eleva del cerro (Uroz Sáez, Poveda y Márquez, 2006; Uroz Sáez y Márquez, 2002). El material recuperado bajo el derrumbe de los departamentos ibéricos, en ambos sectores, es ingente, y en muy buen estado de conservación, tanto el ibérico como el de procedencia itálica, ofreciéndonos así una imagen congelada en el tiempo de esta comunidad de origen oretano, pero habituada a la presencia 
romana desde hacía más de un siglo (Uroz Rodríguez, e. p; 2020a; 2020b; 2018; 2015; 2013; 2012; Quesada Sanz y Uroz Rodríguez, 2020; Uroz Rodríguez y Arévalo González, 2020; Uroz Rodríguez y Velaza, 2020a; 2019; Uroz Rodríguez y Uroz Sáez, 2016; Hernández Canchado, 2007; Uroz Sáez, Poveda, Muñoz y Uroz Rodríguez, 2007; Uroz Sáez et al., 2003).

La posición estratégica del otrora poblado ibérico debió ayudarle a recuperarse pronto, pues, hasta que Augusto desarrolló la costera del Sureste que lleva su nombre, la via Heraclea era el único canal de comunicación terrestre que conectaba los antiguos territorios de las provincias Citerior y Ulterior (Cicerón, Ad Fam. 10, 31,1; Estrabón, III, 4,9; Sillières, 1999), de especial valor desde el otoño hasta la primavera, épocas en las que no se podía navegar por el Mediterráneo. Como sabemos por el pasaje de Estrabón (III, 4,9), fue también la vía que utilizó Julio César, en una veloz marcha de 27 días, refrendada también por Apiano (b.c. II, 103) aunque Suetonio (Julio César, $56,5)$ la reduce a 23 , para llegar durante el invierno desde Roma a Obulco (Porcuna, Jaén), donde tenía concentrado su ejército al mando de sus generales Q. Pedio y Q. Fabio Máximo, en los episodios que condujeron a la gran batalla de Munda (en marzo del 45 a.C.), en el marco de la guerra civil contra Pompeyo y sus hijos. Tras sofocar la rebelión de la Ulterior, finalizada la guerra y antes de regresar a Roma, César acomete una serie de reformas, conocidas parcialmente por el bellum hispaniense y Dión Casio (XLIII, 39,5). Para anular definitivamente la resistencia pompeyana en la Ulterior, César castigó a las ciudades pro-pompeyanas con una ingente confiscación de tierras y con la imposición de pesadas cargas fiscales, mientras que a las que habían permanecido fieles las premió con exenciones de impuestos, y con la elevación de su estatuto político-administrativo, unas como colonias, otras como municipios de derecho romano (Roldán, 2001, pp. 303-310): convierte en colonias Hasta Regia, Iulia Romula Hispal, Itucci Virtus Iulia, Genetiva Iulia Urbanorum Urso, Iulia Gemella Acci; reconvierte a Cartagena en colonia Iulia, y asciende a municipio romano a Castulo, ciudad oretana como la estratégi- 
ca Libisosa. En ese contexto no parece improbable que elevara al oppidum de Lezuza al rango administrativo de forum (Uroz Sáez, 2012, pp. 102-105), como en el caso de Iliturgi Forum Iulium (Plinio, III, 10), para encargarse de canalizar las funciones públicas y religiosas del estado romano, ejercer de centro comercial en esta zona estratégica poco urbanizada, y servir como punto de apoyo para el tránsito seguro de las mercancías así como del desplazamiento del ejército y los miembros de la administración pública (Poveda, 2002). A esa fase podríamos asignar la inscripción funeraria de L. Cornelius (Abascal, 1990, pp. 45-49; Abascal y Sanz, 1993, pp. 24, 35) hallada en la vega del río Lezuza, a pocos metros de la ciudad, y que representa el primer testimonio de un ciudadano romano en Libisosa. Si el nomen Varisidia del personaje femenino objeto de la dedicatoria parece denotar un origen itálico de la familia (Uroz Rodríguez y Velaza, 2019b, p. 310, n. 8), la adscripción del dedicante a la tribu Sergia (en vez de la Galeria, propia de la colonia ${ }^{2}$ ) podría asociar su llegada a época cesariana, atraída por las ventajas del nuevo status jurídico. A esta misma fase parecen pertenecer unas estructuras residuales, bajo el pavimento de la plaza del foro, alguna de los cuales se sobrepone a un depósito votivo efectuado en el momento de la destrucción de las guerras sertorianas (Uroz Rodríguez, 2012, pp. 27-234, 419-446). A esa etapa también atribuíamos inicialmente (Uroz Sáez, 2012, p. 104; Uroz Sáez, Molina, Poveda y Márquez, 2004, pp. 187-190; Uroz Sáez, Molina y Poveda, 2002, pp. 245-251) el muro en forma de L mayúscula (UE 149/203) ubicado al noreste del foro (Fig. 2), con una orientación diferente, y que «aterraza», aunque no de forma definitiva, la pendiente de la colina que buza al norte. Sin embargo, la campaña de excavaciones de 2020 , como veremos enseguida, ha sacado a la luz otra realidad bien diferente.

\footnotetext{
${ }^{2}$ Tal y como pone de manifiesto la inscripción (CIL II, 4254) hallada en Tarragona con un ilustre libisosano convertido en flamen provincialis de la Citerior en época de Adriano (Alföldy, 1975, nº 313)
} 


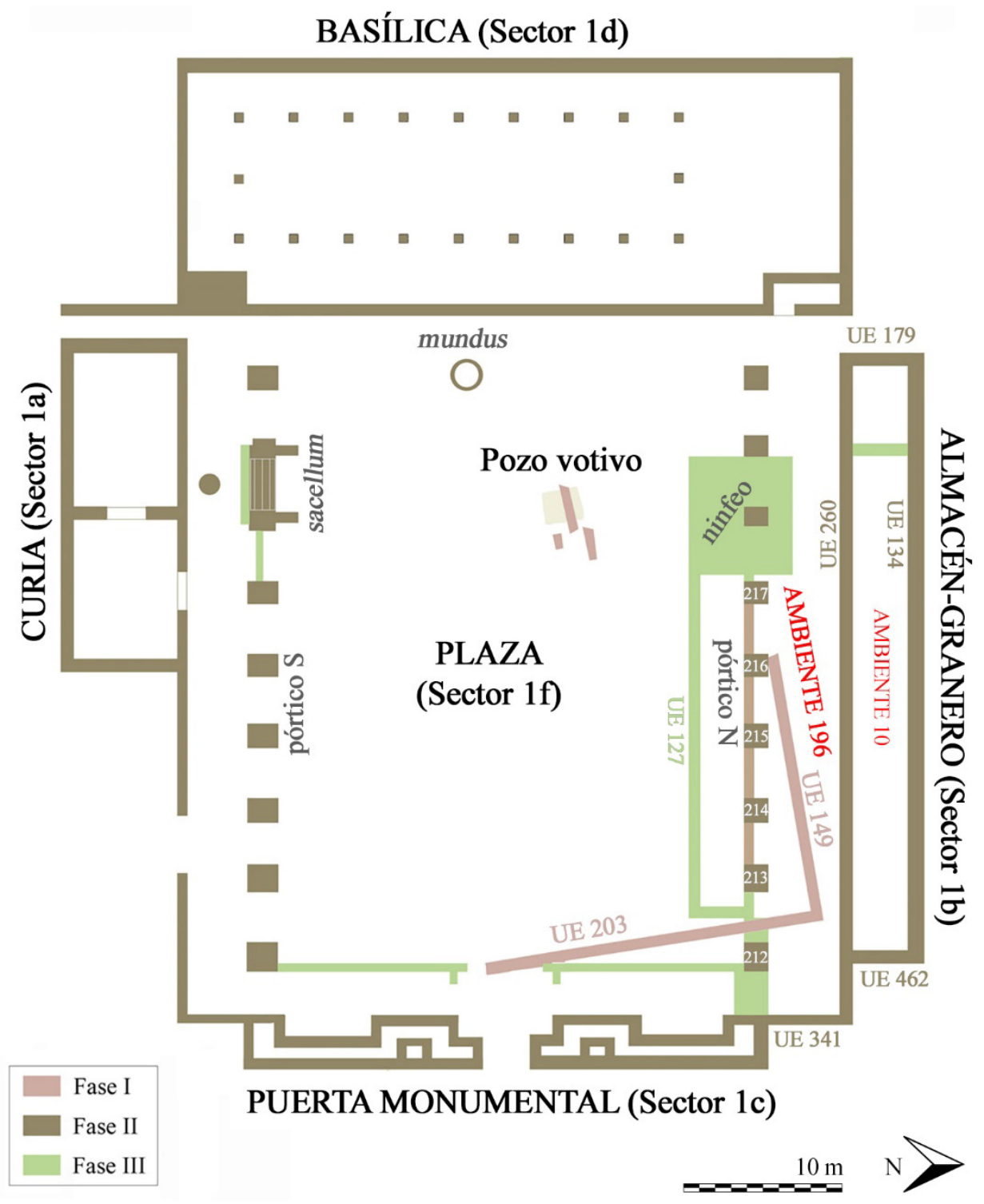

Figura 2. Planta del foro de la colonia romana, con indicación de sus elementos más destacados e interpretación de las fases constructivas (con anterioridad a la campaña de 2020)

La promoción de este antiguo oppidum oretano concluye, tras la etapa de forum, con su conversión en la colonia Libisosa Foroaugustana, a la que Roma le confirió el ius italicum (Plinio, III, 25). Se 
trata de la más alta consideración jurídica que otorga Roma, y que en Hispania la ostentan solamente Acci (de cognomen Iulia, que fue planificada por César en el 45 a.C. aunque su fundación la llevó a cabo Augusto, con los veteranos de la legio Vernacula y la legio II) y Libisosa, y que afecta a tres poderes esenciales (Uroz Sáez, 2012, pp. 105-107; González Román, 1991; 1994; Mazzarino, 1974, pp. 357372; Luzzato, 1974, p. 20): las ciudades que lo poseen quedan exentas del control del gobernador provincial, sus ciudadanos son jurídicamente capaces de ser plenamente propietarios de la tierra que la limitatio les ha asignado, y están exentas de los impuestos que gravan a las comunidades provinciales (el tributum soli y el tributum capitis). La única noticia sobre la fundación de la colonia romana de Libisosa se la debemos a la descripción que Plinio el Viejo realiza de Hispania. La opinión común es que este autor toma la mayor parte de la información de una fuente de época augustea (Beltrán Lloris, 1999, pp. 248-251), del censo de Marco Agripa (muerto en el 12 a.C.), yerno de Augusto, al que el mismo Plinio se refiere en alguna ocasión (III, 17). Es decir, con anterioridad al año 12 a.C. Libisosa ya debió ser colonia (Uroz Sáez, 2012, pp. 105-109). Además, solo Augusto concedió el ius italicum a ciudades hispanas (D’Ors, 1974, p. 261). De hecho, el común de la historiografía que se ha ocupado del tema, antes o después de nuestras excavaciones, consideran augustea a la colonia (García y Bellido, 19611962, p. 371; Galsterer, 1971, p. 71; Roldán, 1975, p. 246; Alföldy, 1987, pp. 31-32; Tovar, 1989, p. 178; Sanz, 1989; Carrasco, 2009-2010, pp. 160-163; Andreu, 2008, pp. 232-233; Ortiz Córdoba, 2019). Pero, además, las excavaciones que se han podido retomar en el foro en los últimos años han proporcionado abundantísimo material de importación que certifica la fecha augustea para la creación de la colonia, tal y como iremos rindiendo cuentas tanto en este como en próximos trabajos.

El foro romano colonial (Fig. 2) se encuentra perfectamente orientado de este a oeste, articulado en torno a una gran plaza de 44 $\mathrm{m}$ de longitud por $29 \mathrm{~m}$ de anchura, para lo cual se tuvo que proceder a rebajar la colina en su parte sur y a la creación de un potente 
relleno en su parte norte (Uroz Sáez et al., 2004, pp. 187-190; Uroz Sáez, Molina y Poveda, 2002, pp. 245-251). El ingreso principal se halla en su fachada oriental, el sector $1 \mathrm{C}$, que da acceso a sendos pórticos, a derecha e izquierda respectivamente. El lado meridional de la plaza (sector 1A) está ocupado por el pórtico cubierto desde el que se accede a la curia (a través de una puerta de 2,30 m de anchura, de la que se conservan intactos el umbral y una jamba), compuesta de dos estancias, la primera pavimentada con opus spicatum, y la segunda, al oeste, en opus signinum. En el lado occidental del foro (sector 1D) está situada la basílica, con dos accesos desde la plaza en las áreas porticadas. En el eje central del foro, y próximo al podio de la basílica, se halla el agujero del mundus. No han sido halladas huellas de ningún templo durante la excavación del foro de la colonia, pero sí un sacellum en el pórtico sur, delante de la curia, destinado seguramente al culto imperial.

En la parte norte de la plaza forense, el sector 1B, se halla un pórtico idéntico al meridional, detrás del cual se desarrolla un gran edificio de $35 \mathrm{~m}$ de longitud orientado de este a oeste (ambiente 10), que debió estar destinado seguramente a almacenar grano, y que se construyó amortizando edificios ibéricos preexistentes. Pero, como se ha mencionado, para que la plaza forense de la colonia romana fuese tan amplia casi en la cúspide de esta colina, los ingenieros romanos tuvieron que acometer la tarea de rellenar con un potente estrato la zona norte del foro, donde tiene una gran pendiente, desde el pórtico hasta el granero. La presión que ejercía este relleno sobre el muro perimetral sur del horreum, en coincidencia seguramente con un movimiento sísmico, produjo la destrucción del edificio ya en el Alto Imperio, del que pudieron reaprovechar apenas su extremo oeste, cancelando el resto con un muro (UE 127) al sur del pórtico y añadiendo un ninfeo (Muñoz Ojeda, 2004). Y es en este sector, de la mano de una serie de actuaciones de consolidación y puesta en valor, en el que se han centrado las últimas actuaciones en esta zona del yacimiento (Fig. 3). 

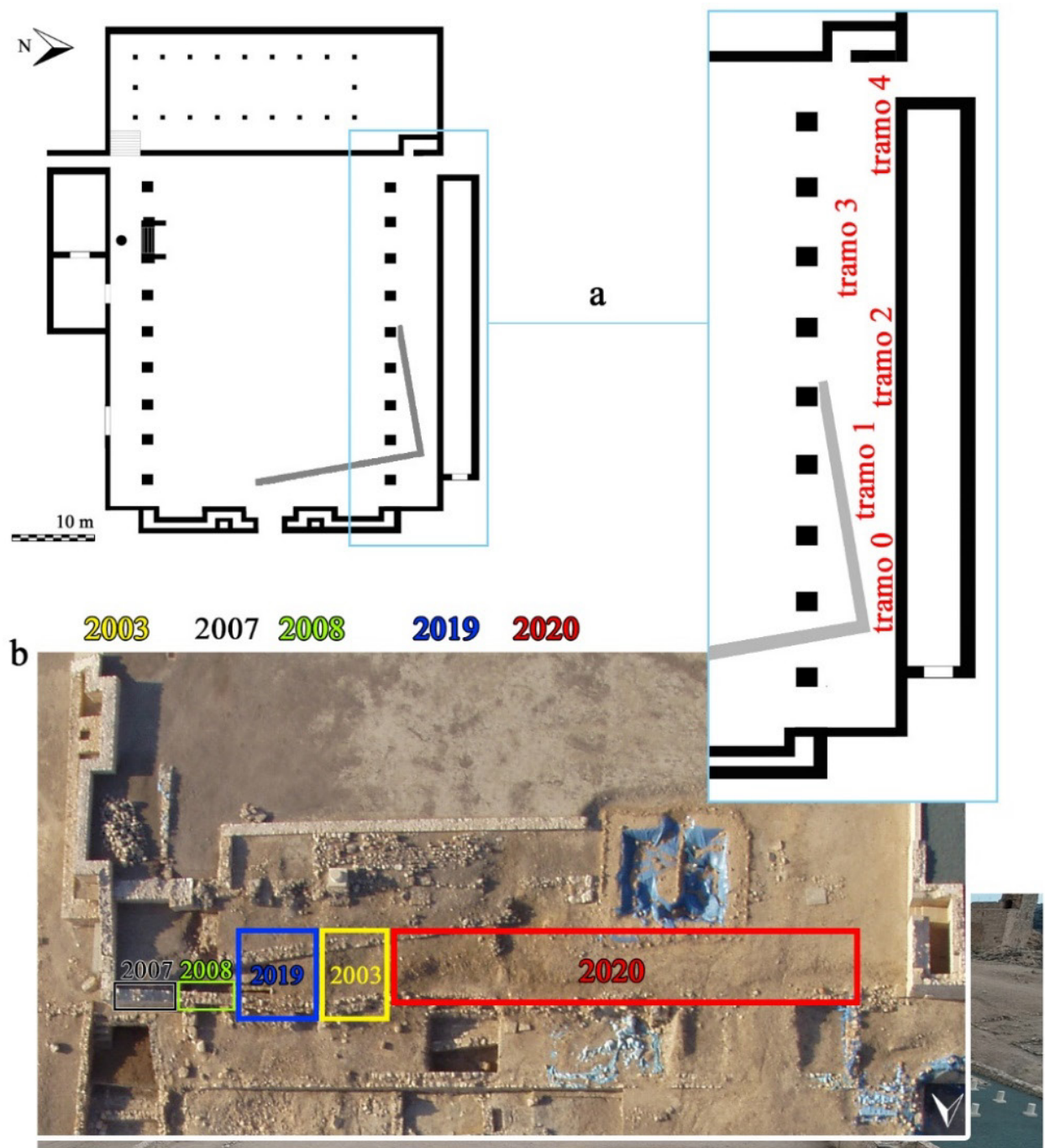

c

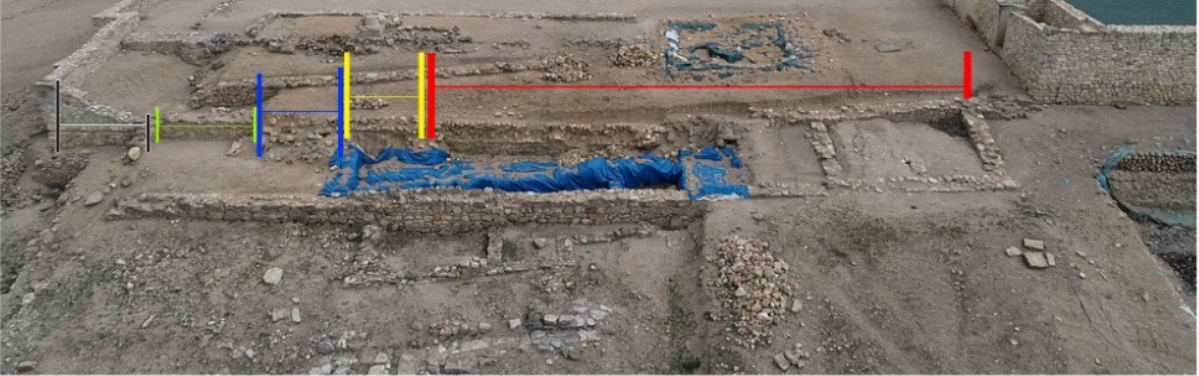

Figura 3. a. Planta del foro en su fase fundacional con detalle de división en tramos del ambiente 196;

b. campañas de excavación efectuadas en el ambiente 196 sobre foto de 2008; c. vista aérea de la zona en 2018 


\section{EXCAVACIÓN DEL AMBIENTE 196 DEL SECTOR 1B}

El ambiente 196 se encuentra entre el edificio interpretado como horreum (ambiente 10) y el pórtico septentrional de la plaza; concretamente se trata del espacio existente entre el muro UE $260^{3}$ por el norte, el muro UE 149 y el ninfeo UE 181 por el sur, la basílica por el oeste, mientras que por el este cierra el muro UE 341 (Fig. 2), área que, por su longitud, dividimos en 4 tramos durante el proceso de excavación (Fig. 3a). Dicho ambiente había sido parcialmente intervenido en campañas precedentes. Tomando como punto cero el ángulo interior formado por los muros UE 260 y 341, y midiendo en paralelo a la cara sur del muro 260, el tramo entre 0 y 4,60 m había sido excavado (y recolocado el muro 260 en posición vertical) en la campaña de 2007; entre 4 y 8,60 m lo fue en la campaña de 2008; el tramo ubicado entre 8,60 y 12,40 m había sido en parte excavado en 2019 , y entre las distancias 12,40 y 15,00 m corresponde a la cata efectuada en 2003 (Fig. 3b-c).

En la campaña de 2003 se practicó un sondeo N-S de 2,50 x 2,70 m entre los muros UE 149 y 260, con el objetivo de documentar la cimentación de estas dos estructuras y clarificar la relación estratigráfica entre ambas. De los resultados de aquella excavación, y de los obtenidos en las siguientes campañas, evitaremos, como ya se ha señalado, una descripción detallada de cada unidad estratigráfica, de las que se ofrece, no obstante, un significativo resumen, suficientemente ilustrador. En la parte sur del sondeo, apoyándose en el muro UE 149, se hallaba la UE 1583 (Fig. 4), formada por una tierra anaranjada de textura arcillosa con abundantes cantos rodados, y bajo ella un estrato de marga de color verdoso de una gran dureza con piedras de pequeño tamaño (UE 1586), mientras que en la parte norte, y apoyando en el muro UE 260, apareció la UE 1584, compuesta por una tierra de color marrón oscuro y textura arenosa con piedras de pequeño tamaño, cantos rodados y carbón. Los materiales aportados por estos

\footnotetext{
${ }^{3}$ Trataremos de mencionar las unidades estratigráficas (UE) indispensables, para ofrecer un texto de lectura más ágil.
} 
estratos son de cronología republicana, básicamente cerámica ibérica y escasos fragmentos de cerámica de barniz negro y de paredes finas. Bajo dichas unidades, y ocupando toda la extensión del corte, la UE 1594, compuesta por una tierra de color parduzco, de textura arcillosa con abundantes fragmentos de carbón y adobe disgregado y algunas piedras de mediano tamaño, que aportó cerámica ibérica pintada, de barniz negro, así como paredes de ánforas romanas de cronología republicana. Bajo ella, una franja de marga de color verdoso de gran dureza y piedras de mediano tamaño, la UE 1674. Finalmente, los dos últimos estratos: al sur, la UE 1682 (bajo 1674), formado por tierra de color grisáceo, fragmentos de adobes, carbones y algunas piedras de mediano y pequeño tamaño, con fragmentos de cerámica común, de ánforas ibéricas, cerámica ibérica pintada, y de un ánfora itálica Dr 1. En la mitad norte apareció otro estrato (UE 1675) de tierra rojiza de textura arenosa con escasos restos de carbón y algún material cerámico (ánforas ibéricas, cerámica común e ibérica pintada). Se pudieron vislumbrar, en esta campaña, los cimientos de los muros 149 y 260, las unidades 1944 y 1945 -respectivamente- (Fig. 4), que documentaríamos en toda su extensión en la campaña de 2020. 

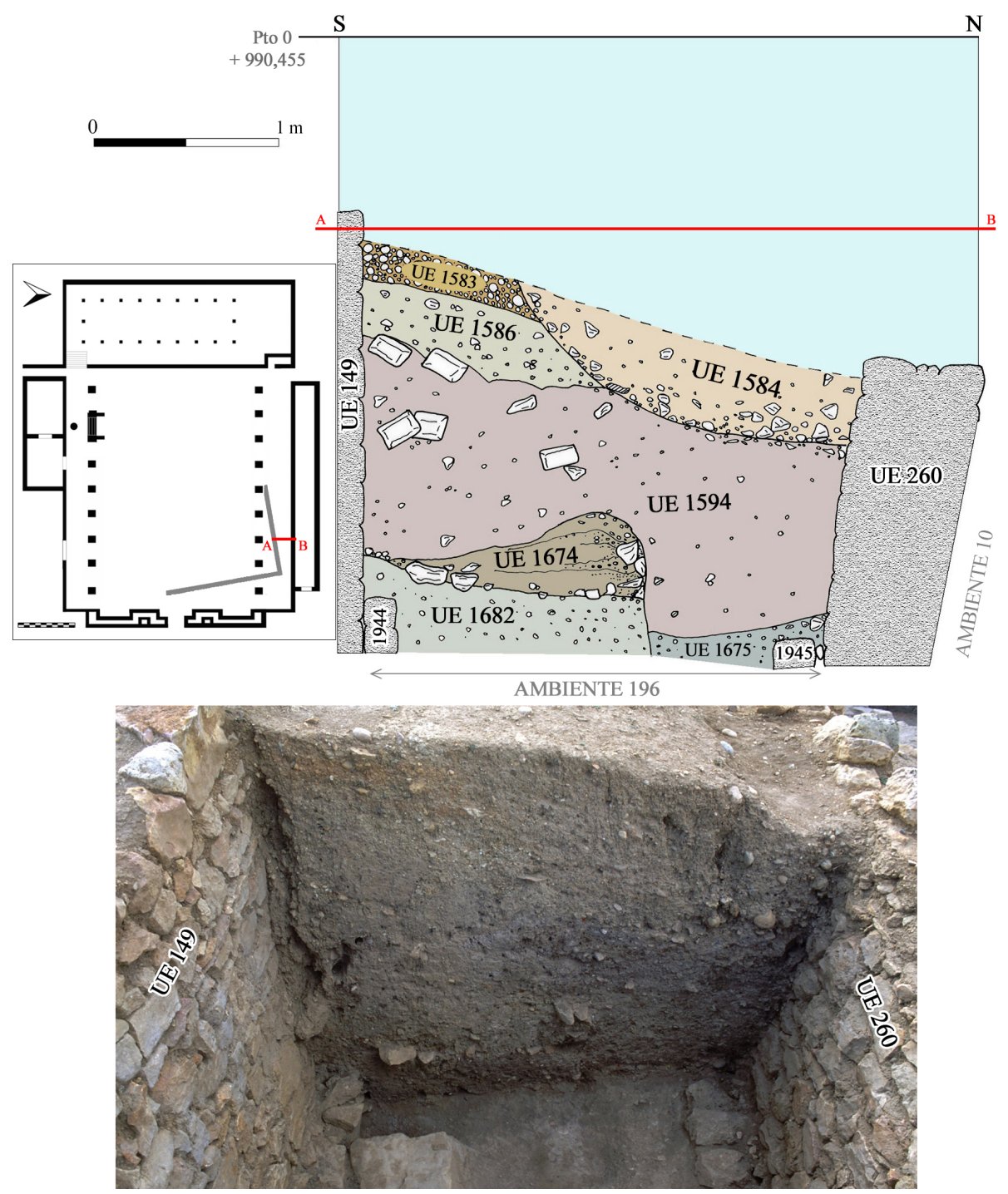

Figura 4. Sección de la intervención de la campaña de 2003 en el ambiente 196 e imagen del corte

En el contexto de la consolidación de los edificios del foro, una de las tareas emprendidas en la campaña del año 2008 (Fig. 3bc) fue continuar con el proceso de anastilosis iniciada en la campaña anterior, consistente en recolocar, en posición vertical, un corto tramo (4 m de L) del muro 260 en su extremo este, que había sido desplazado hacia el norte, y que había producido el derrumbe del 
edificio del horreum, del que constituía su muro perimetral sur. Para ello fue necesario practicar un corte longitudinal en ambas caras del muro, hallándose básicamente las mismas unidades estratigráficas que en el sondeo de 2003, ubicado a muy poca distancia (Fig. 5). No se encontró material de relevancia (exceptuando algún fragmento de cerámica de cocina y común) que nos aportara datos cronológicos más precisos.

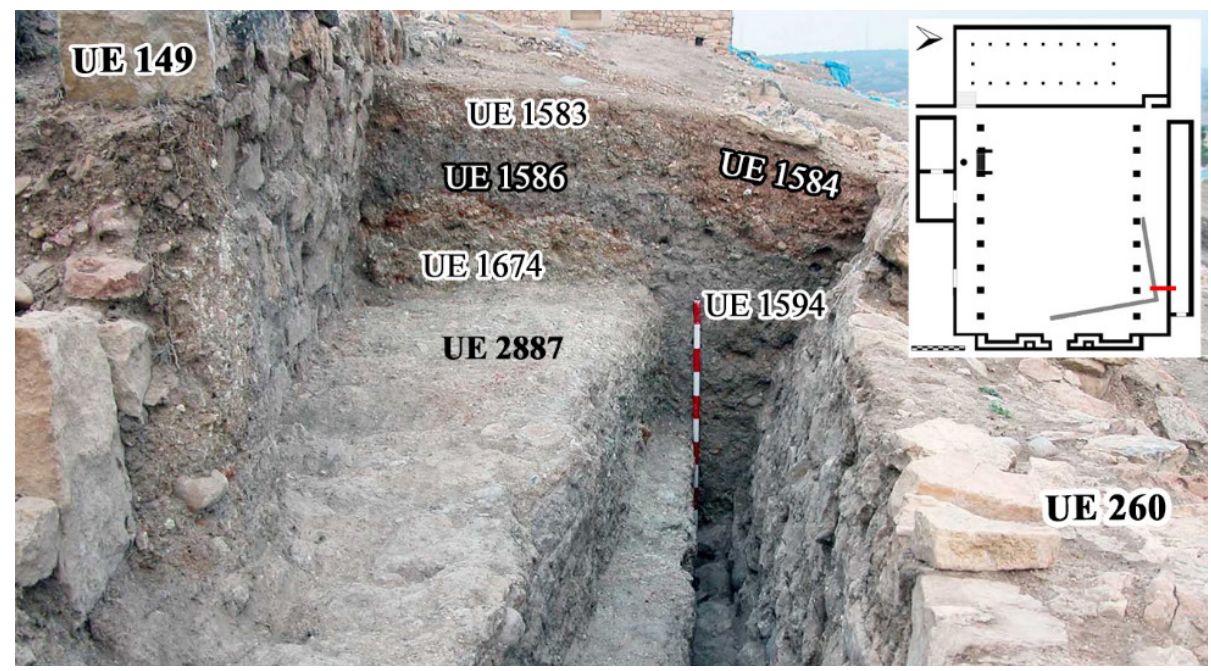

Figura 5. Estratigrafía de la intervención de la campaña de 2008 en el ambiente 196

La intervención en esta zona en la campaña de 2019 tuvo un carácter más puntual. Durante el proceso de excavación del ambiente 10 se produjeron, a mitad de septiembre, unas tormentas catastróficas que afectaron a todo el sureste español, y también al yacimiento, con el derrumbe de parte del muro UE 260 en la zona de trabajo (Fig. 6a-b), debido a su pronunciada inclinación. Para evitar peligros de nuevos desprendimientos, se inicia la excavación del tramo situado al sur de dicho paramento, una estrecha franja $(4,75 \mathrm{~m}$ en sentido longitudinal E-W, y 2,40 de N-S) ubicada entre aquel y el muro UE 149, justo al este del sondeo realizado en la campaña de 2003. Y encontramos la misma secuencia que entonces: bajo el estrato UE 1583, compuesto de zahorra y guijarros de pequeño tamaño (cotas MM.S.N.M. de 986,16 m en la parte sur, y 985,65 en la 
norte), y que proporcionó poco material (fragmentos de paredes de cerámica común, algo de fauna), aparece la UE 1586 (Figs. 5, 7), un estrato de marga de color verdoso de una gran dureza con piedras de pequeño tamaño, a una cota de $985,78 \mathrm{~m}$ en la parte más alta (la sur), junto al muro UE 149, mientras que en la parte norte, junto al muro UE 260, hallamos, como en 2003, la UE 1594, a una cota de 985,54 m, un estrato de tierra marrón grisáceo, con piedras y guijarros de pequeño tamaño, y fragmentos de adobe, mucho menos compacta que la unidad 1586. Por no ser necesario en esa campaña, a una cota de 985,60 m dejamos de extraer la UE 1586 (que no proporcionó ningún material) y nos centramos en la UE 1594, que continuamos extrayendo, en paralelo al muro UE 260 (con una anchura de 2,40 m), hasta una cota de 984,19 m, donde apareció una hilada de piedras de mediadas dimensiones, trabadas sin argamasa, en paralelo al muro 260, la UE 1945 hallada en el control de 2003, o lo que es lo mismo, la cimentación de dicho muro. De esta UE 1594 se exhumaron abundantes materiales: fragmentos de ánforas ibéricas y romanas republicanas, cerámica ibérica pintada (incluyendo un borde de kalatos), barniz negro y abundante cerámica común y de cocina ibérica y romana; así como fragmentos de clavos y láminas de hierro, y numerosos restos faunísticos.

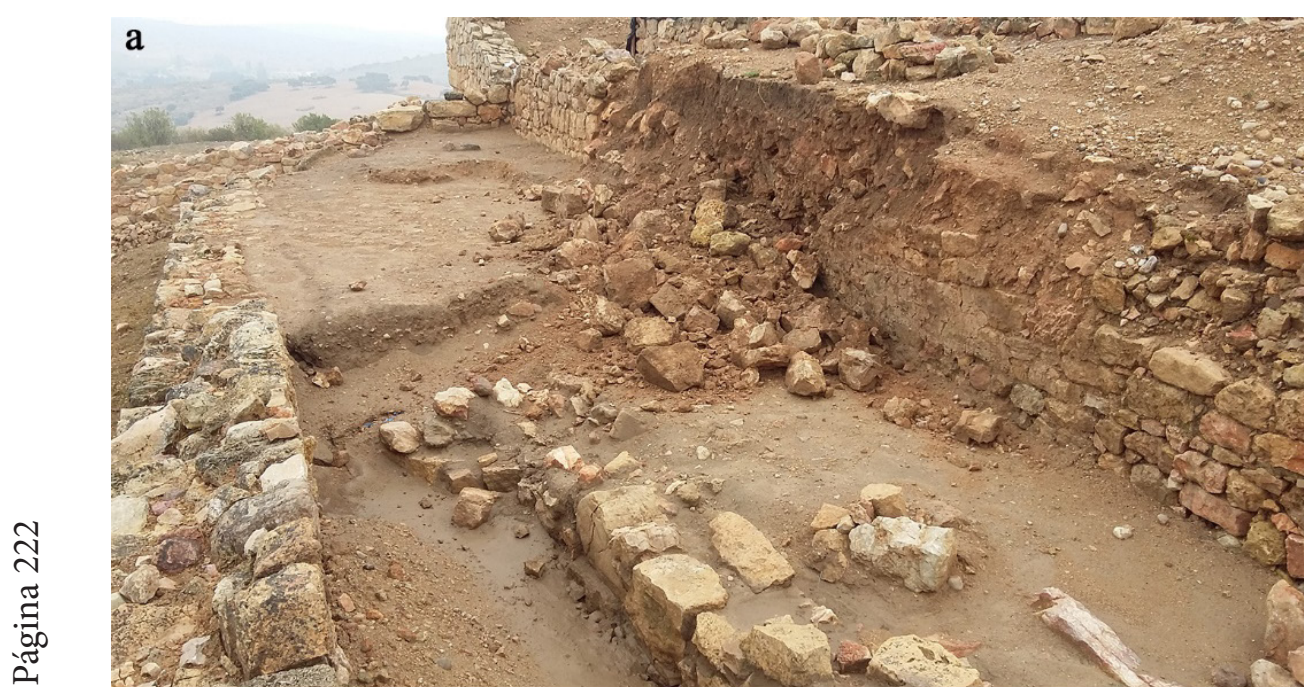




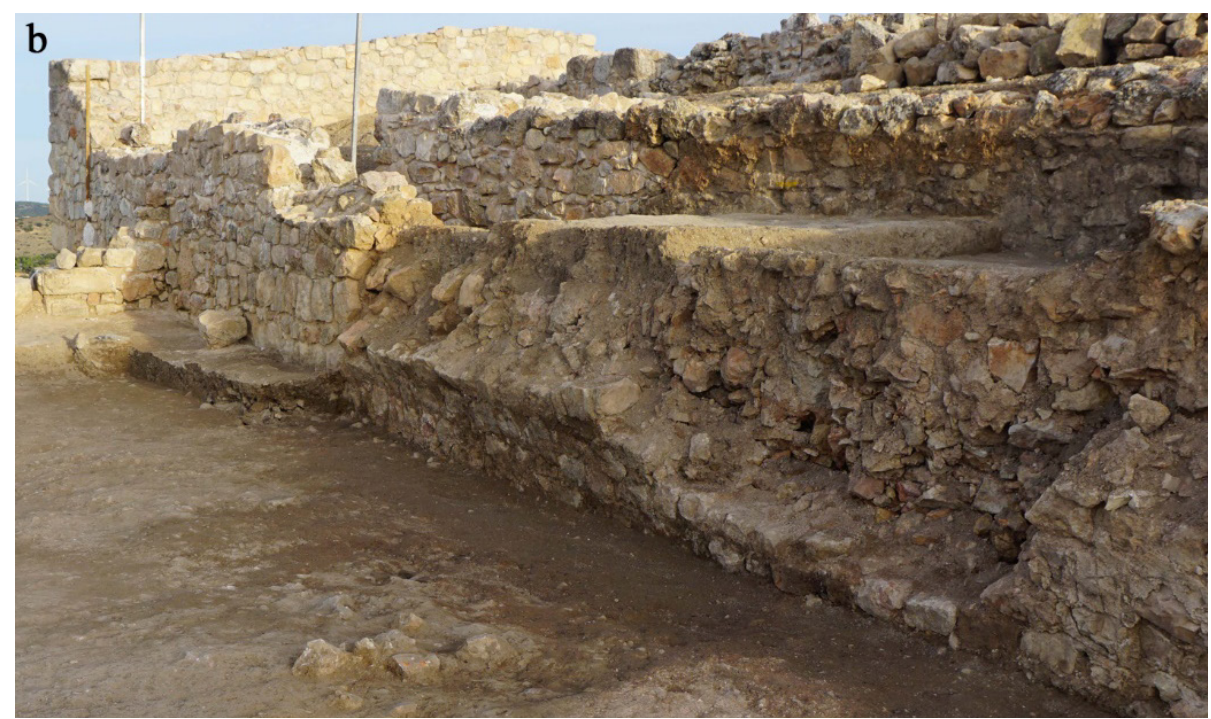

Figura 6. a. caída del paramento norte del muro UE 260, tras las fuertes lluvias;

b. estado de deterioro del interior del muro, fracturado por su inclinación

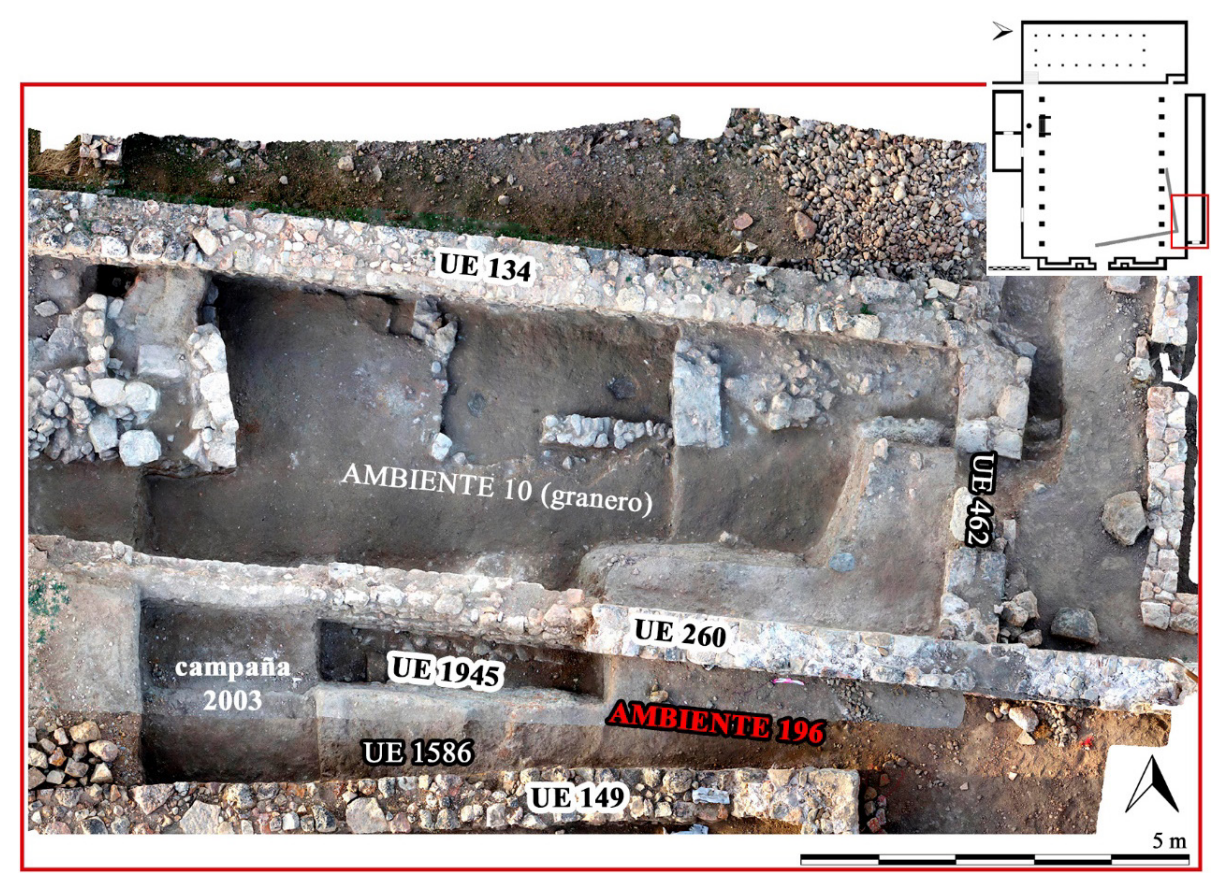

Figura 7. Ortofoto de la situación de la intervención en el ambiente 196 al término de la campaña de 2019, con la aparición de la UE 1945 (a partir de fotogrametría de J. L. Fuentes) 
Para el verano de 2020, uno de los objetivos programados fue continuar con los trabajos efectuados en las campañas precedentes en el ambiente 10 (el granero de la colonia), así como los iniciados al sur del muro UE 260 (ambiente 196), con el objetivo de seguir obteniendo información sobre la fecha de su construcción (y, por tanto, de la fundación colonial) y, al mismo tiempo, y de forma coordinada con una acción de consolidación y puesta en valor, corregir la pronunciada inclinación hacia el norte del muro 260 en los tramos pendientes.

En lo que respecta al ambiente 196, la estratigrafía que hallamos es similar a la documentada en las campañas precedentes, como algunas pequeñas intrusiones residuales de la UE 1583, compuesta por zahorra muy compacta de color rojizo/teja, con fragmentos de este último material y de adobe, que ha proporcionado un registro material que incluye paredes y asas de ánfora romana, fragmentos de barniz negro de producción napolitana y calena, escasa terra sigillata, abundante cerámica ibérica (tosca y fina, pocas pintadas y grises, algo de ánfora), muchos restos óseos de fauna, fragmentos de hierro, y parte de una fíbula de bronce. Tras lo cual apareció la UE 1586 (Fig. 8), a una altitud que oscila entre los 986,285 y los $986,001 \mathrm{~m}$, de la que apenas extraemos pocos cms, y de ahí el poco material hallado (fragmento de ladrillo romano, cerámica ibérica -pintada, gris, tosca-, y poca fauna). 


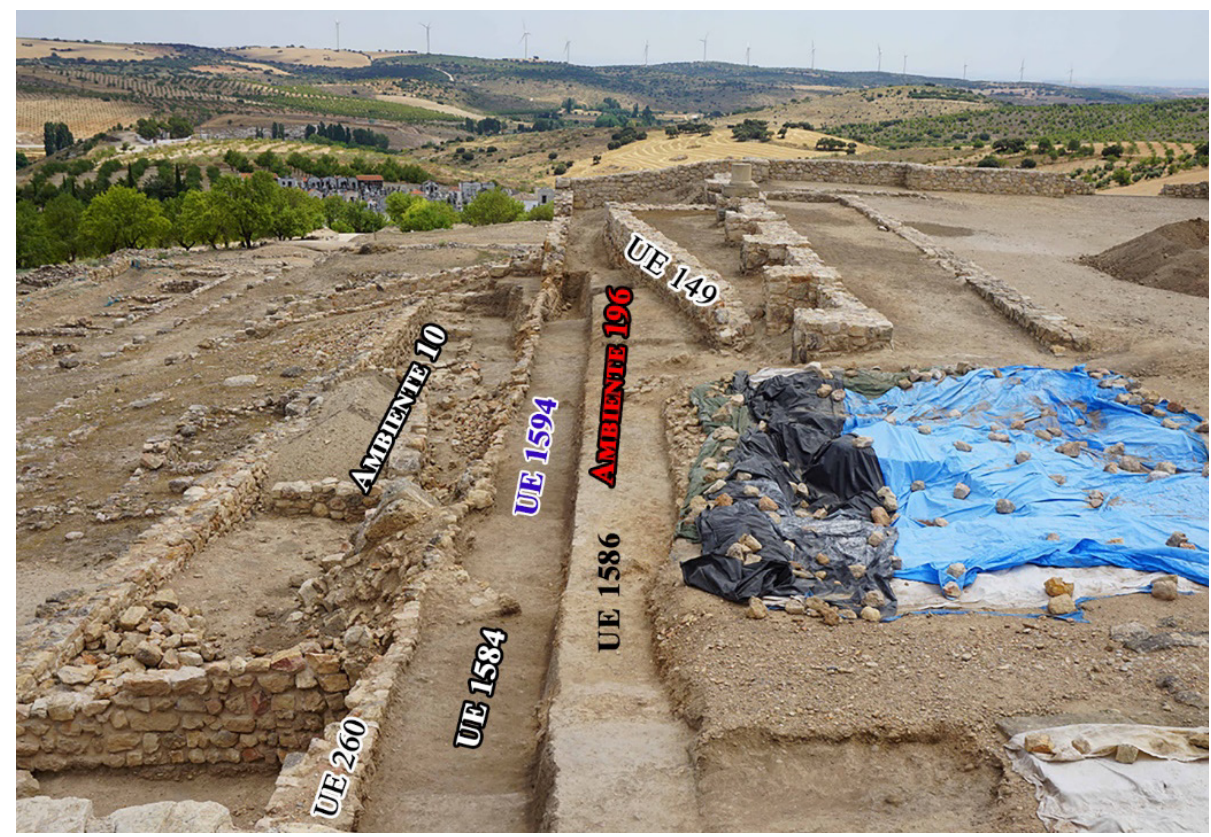

Figura 8. Panorámica de la intervención de 2020: extracción de las UE 1584 y 1586, e inicio de la extracción de la UE 1594

Sin profundizar ya más en la UE 1586, se procedió después a la extracción de la UE 1584 en todo el ambiente, pero solo en una franja paralela al lado sur del muro UE 260, que se extiende en una anchura de 1,20 por término medio (dependiendo del grado de desplazamiento de aquella estructura), un estrato que se conformó al rellenarse, con material de la capa superior, el hueco formado cuando el muro se inclinó hacia el norte y se destruyó el edificio. Dicho estrato está compuesto por tierra suelta, sin piedras procedentes de derrumbe, pero sí fragmentos de tejas y adobes junto a abundante material cerámico, predominantemente ibérico: pequeños fragmentos de tosca y fina (algunos pintados y grises, destacando una imitación de L 5 de gran tamaño), paredes de ánfora, y fauna. También se ha recuperado parte de un ánfora romana republicana, y un fragmento de borde de plato de sigillata itálica Consp 19 var 3.1 (cronología: 1-30 d.C.) ${ }^{4}$.

\footnotetext{
${ }^{4}$ Agradecemos a José Luis Fuentes, director de Oppida S. L. y miembro del equipo, su ayuda en la catalogación de la cerámica sigillata.
} 
Bajo esta capa, y a una altitud que oscila entre los 985,362 y los 985,265 m, se halla la UE 1594 (Fig. 8), compuesta por tierra parduzca suelta, muchos fragmentos de teja, algunos de adobe y de ladrillo, carboncillos, y abundante material cerámico. Se trata de la tierra (y el material residual acompañante) con la que se rellena la zanja practicada para construir el muro UE 260 (el perimetral sur del horreum), que debe soportar tanto la techumbre de dicho edificio como la del pórtico anexo por su lado sur, es decir, el pórtico norte de la plaza forense. Esta unidad estratigráfica ha proporcionado un gran cantidad de material (en proceso de estudio, como el de los demás estratos): como es común, se ha recuperado abundante cerámica ibérica, mayoritariamente en pequeños fragmentos (tosca y fina, ánfora, pintada, de barniz rojo, gris, y una imitación de copita L 2 en cocción reductora), varios fragmentos de barniz negro de producción napolitana -«Campaniense A»-, cerámica común romana (incluyendo fragmentos de borde de mortero), varios fragmentos de galbo, borde y asa de ánforas romanas republicanas, varios clavos y argollas de hierro, fragmentos de plomo (entre ellos, una plancha rectangular de unos $15 \mathrm{~cm}$ de longitud), y muchos restos faunísticos, como también es habitual. Entre este registro material cabe destacar una piquera de lucerna Dressel 2 itálica (s. I a.C.), otro pequeño fragmento de disco con decoración oval, un pequeño fragmento de paredes finas, un fragmento de borde/pared de cáliz de TS itálica Consp R5 var 2.1 (10 a.C.- 15 d.C.), una piedra de molino de $0,30 \times 0,26 \mathrm{~m}$, una pesa de telar, restos de una pequeña hoz o podadera de hierro, y puente y medio anillo de fíbula anular hispánica de bronce.

La cara sur del muro UE 260 presenta (como en la norte) un hueco longitudinal en forma de U mayúscula (UE 3635) a mediana altura (Fig. 10), dentro del cual (UE 3641) se hallaron varios clavos de hierro para sujetar la madera que ocupaba este espacio regulador de enrase y andamio, además de tierra fina y carboncillos. Dicha oquedad se conserva en una longitud de 14,30 m, la altura oscila entre los 8 y $11 \mathrm{~cm}$, y su profundidad $15 \mathrm{~cm}$ de media. La cota 
es prácticamente la misma: tomando como punto 0 el ángulo exterior formado por los muros UE 179 y 260 , a $4 \mathrm{~m}$ la altitud de dicha oquedad es de 985,412 , a $6,40 \mathrm{~m}$ es 985,420 , a 8,50 m su cota es de 985,384, y a $12,30 \mathrm{~m}$ es 985,40 .

El enrase de los cimientos del muro UE 260 ya había sido descubierto, en su nivel superior, en el sondeo efectuado en 2003: se trata de la UE 1945. En la campaña de 2020 quedó evidenciado en toda su longitud y altura (Figs. 9-11). La cota de la hilada superior de la cimentación va perdiendo altura a medida que nos acercamos a la parte Este del muro, donde la roca base está también a una cota más baja: tomando como punto cero el ángulo exterior formado por los muros UE 179 y 260 , a 4 m de distancia la altitud del enrase es de 984,906, a 5,30 m es 984,928, a 6,70 m es 984,767, a 8,5 m (984,70), a 17,40 (984,57), a 26,66 m (984,18), a $29 \mathrm{~m}(984,113)$, a 30,40 m $(984,15)$, a $32,30(984,202)$.

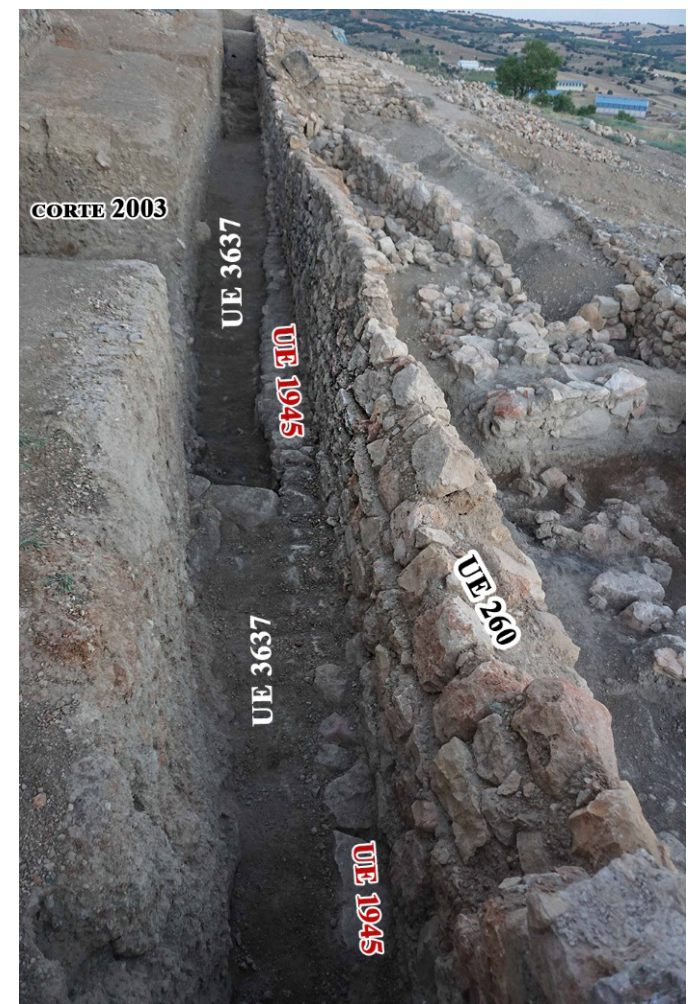

Figura 9. Enrase de cimientos UE 1945 en su parte este, y relleno UE 3637 


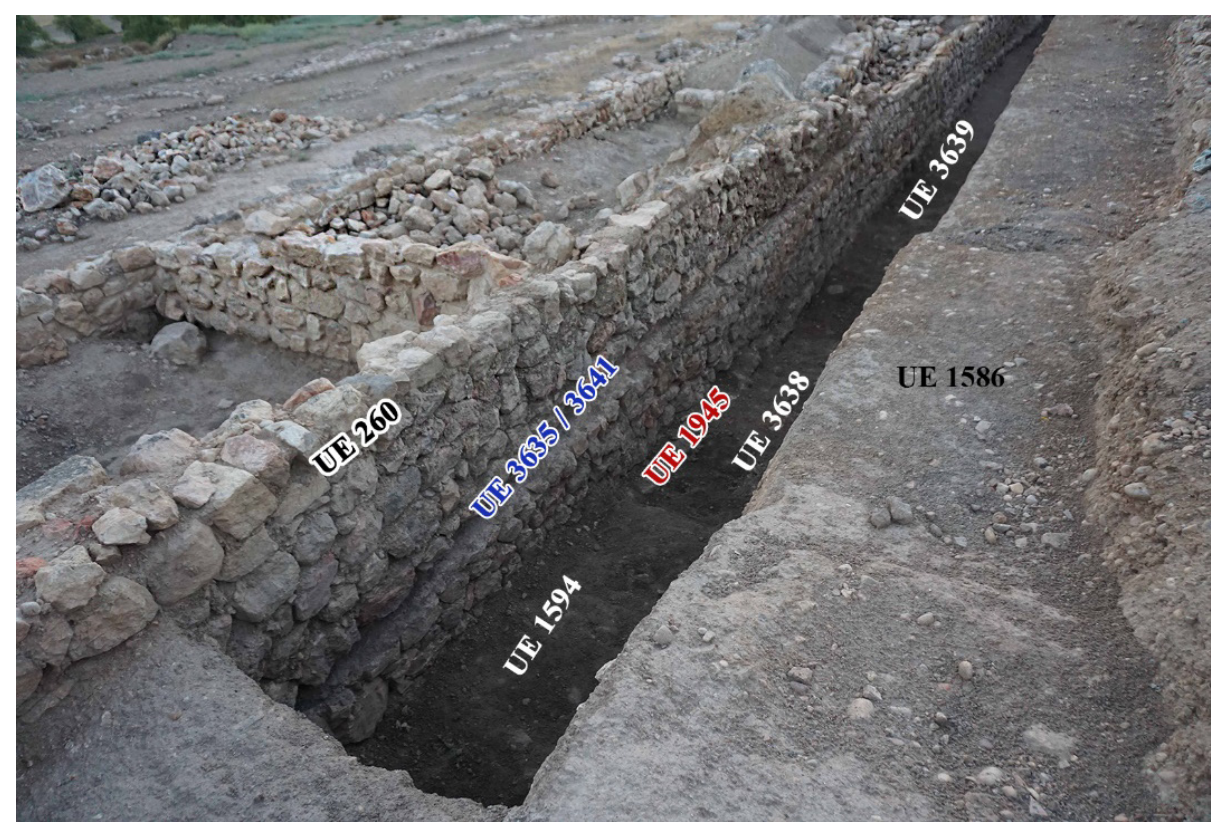

Figura 10. Enrase de cimientos UE 1945 en su parte oeste, y UE 3638, 3639

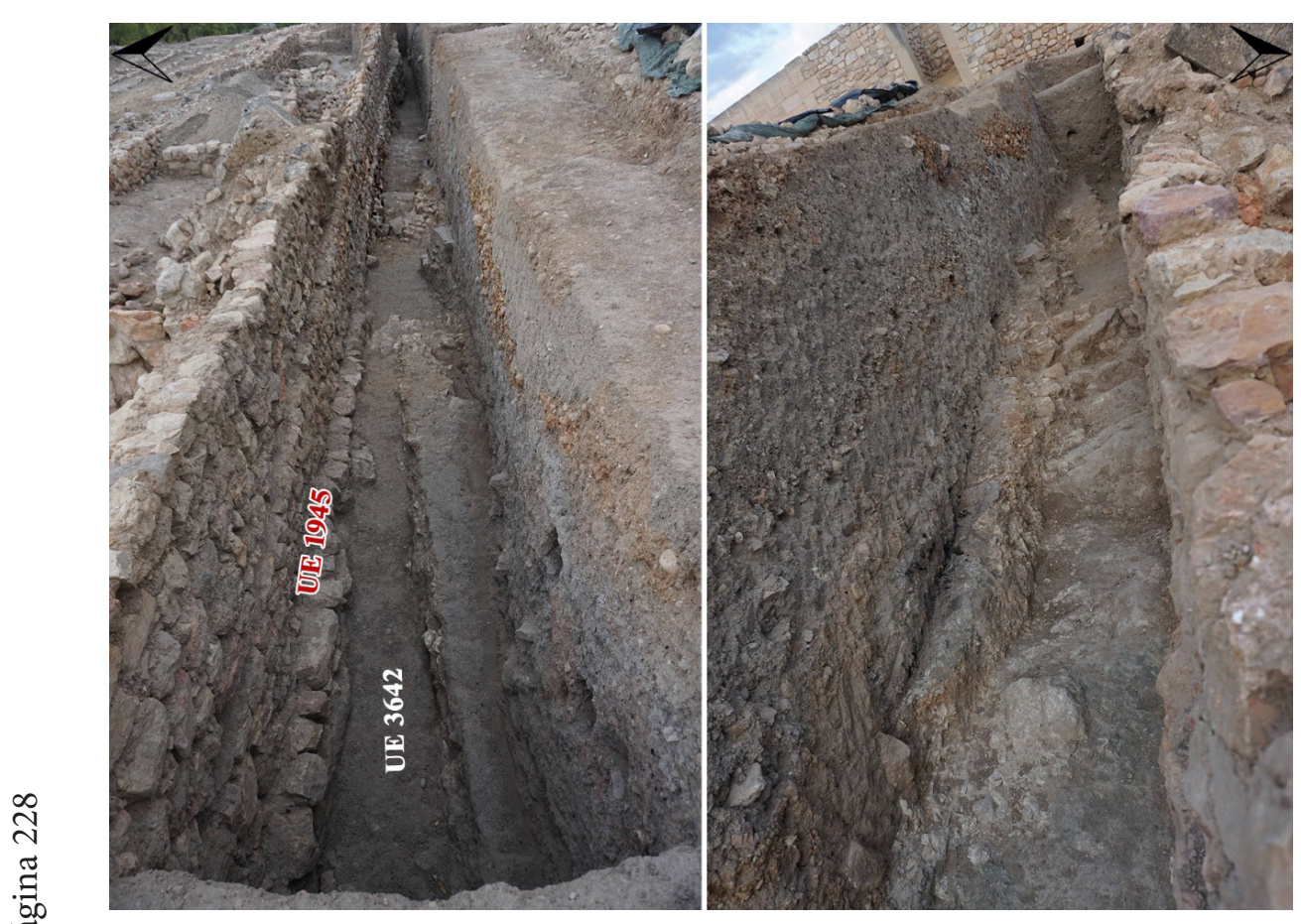

Figura 11. Recorte de la roca base en el tramo oeste del ambiente 196 
Por debajo del nivel marcado por el enrase de los cimientos (UE 1945), y hasta la roca base, se establecieron tres unidades estratigráficas (en función de los tramos) bajo la UE 1594 descrita anteriormente, aunque la composición de las nuevas (creadas por prudencia) era equivalente a la 1594: tierra fina sin piedras y con abundante cerámica residual. La UE 3637 (Fig. 9) corresponde al relleno del ambiente 196 ubicado en los tramos 0 y 1, es decir, las zonas parcialmente excavadas en 2019, 2003 y su inmediato situado al oeste. El material que ha proporcionado es: pared y pivote de ánfora romana (posible L 2), pared con arranque de asa de ánfora Dr 1, fragmento de barniz negro de producción napolitana tardía (L 5), abundante cerámica ibérica (ánfora, gris y tosca, pintada, parte de olla ibérica tosca con grapa de plomo), junto a diversos fragmentos de metal y clavo de hierro, y restos faunísticos varios. Bajo este conjunto se halló la roca base (UE 3683). Por su parte, la UE 3639 (Fig. 10) corresponde al relleno del ambiente 196 ubicado en los tramos 2 y 3 , y ha proporcionado: un fondo de copa de TS itálica indeterminada con sello rectangular interno MVRRIVS (1 a.C.- 15 d.C.), borde/pared de copa de TSI Consp 13 var 2.1 (20-1 a.C.), 2 fragmentos de barniz negro de napolitana tardía, un fragmento de piquera de lucerna, fragmentos de ánfora romana republicana (destacando una pared con arranque de ánfora Dr 1), un fragmento de cerámica rojo pompeyano, mucha cerámica ibérica (sobre todo paredes sin decoración, tosca -algún fragmento con estampillas-, pocos de pintada y pared de ánfora), algunos restos de fauna y 4 clavos de hierro. Bajo este material, como en el caso anterior, se encontraba la roca base (UE 3643). Por último, la UE 3638 (Fig. 10) corresponde al relleno del ambiente 196 ubicado en el tramo 4, y ha dado varios fragmentos de adobe, un pequeño fragmento de pared de copa/bol de sigillata itálica indeterminada, pared de ánfora romana, pocos fragmentos de paredes de cerámica ibérica tosca y fina, así como de ánfora, escorias de hierro y restos de fauna. Bajo esta unidad, hallamos la roca base UE 3642, que había sido recortada en la parte oeste del muro para encajar los cimientos (Fig. 11). 


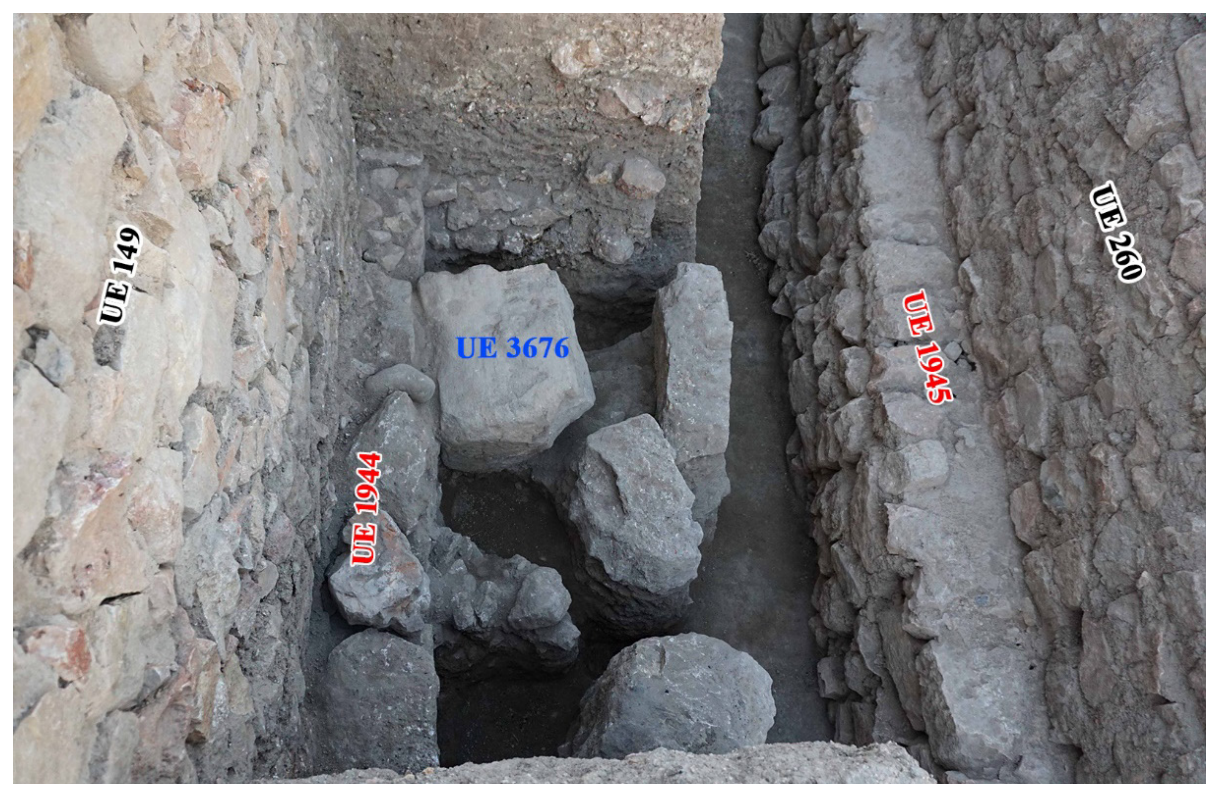

Figura 12. Limpieza del corte realizado en 2003, y composición de la UE 3676

Como ha quedado expuesto con anterioridad, en la campaña de 2003 realizamos un sondeo entre los muros UE 260 y 149 hasta la profundidad marcada por el enrase de sus cimientos, UE 1945 en el caso de la cara sur del muro 260, y UE 1944 en la cara norte del muro 149. Pues bien, concluida la campaña de 2003 en la UE 1682, se cubrió con una tela plástica la unidad estratigráfica no exhumada, y se rellenó de tierra nuevamente para su protección. En la campaña de 2020, tras extraer aquel relleno, y la lona aún intacta, se procedió a su excavación, hallando la UE 3676 (bajo UE 1682), compuesta por piedras de gran tamaño (Fig. 12), bien escuadradas (del mismo formato que las usadas en la construcción de los muros adyacentes), rellenas de tierra y diversos materiales: como es norma en estos contextos, muchos fragmentos de cerámica ibérica (alguna pintada, gris, de cocción reductora y de ánfora), un fragmento de «Campaniense A», un clavo de hierro, y muchos huesos de fauna. Estas piedras, que por tamaño y forma son idóneas para su colocación en el muro, fueron en cambio dispuestas (junto a otra de similar tamaño pegada a los cimientos del muro 260, extraída durante la excavación) a modo de contrafuerte del muro 149. 


\section{LAS ESTRUCTURAS UE 149/UE 3640}

Desde las primeras campañas de excavación practicadas en el foro romano de Libisosa (Uroz Sáez et al., 2002; 2004), se tenía constancia de que el muro UE 149, atribuido entonces a la primera fase (precolonial), en su parte oriental, junto a la base de columna UE 212, giraba en ángulo recto (muro UE 203) en dirección a la plaza forense, penetrando en ella hasta alcanzar la altura de la entrada este del foro (Fig. 2). Sin embargo, parecía desaparecer en su extremo oeste, justo a la altura de la base de columna UE 216. No teníamos constancia, por falta de sondeos, que continuara bajo el ninfeo, o bien girara en este punto hacia el sur, en dirección de la plaza, en paralelo al muro UE 203 ya mencionado. En consecuencia, y en correspondencia con la exhumación del ambiente 196, en la campaña de 2020 practicamos una sección norte-sur en el extremo oeste conservado del muro 149, donde ya se habían extraído previamente las unidades estratigráficas 1583, 1584, 1586, explicadas más arriba. Iniciada, en este punto, la excavación de la UE 1594, se registró en ella una concentración de piedras de mediano tamaño, la UE 3632 (Fig. 13a), y escaso material: un fragmento de ladrillo romano, cerámica ibérica (pintada, tosca, de ánfora), fauna y dos fragmentos de hierro. Con la extracción de este amontonamiento informe de piedras, se pudo documentar, inmediatamente debajo, un muro de dirección NW-SE, la UE 3640 (Fig. 13b), lo que indica que aquellas piedras debieron haber formado parte, de algún modo, de esta estructura, ya fuese colocadas a modo de majano, como refuerzo u obra a medio hacer, aunque también podría tratarse de un sondeo realizado en época posterior (resultado, por ejemplo, de los trabajos agrícolas) que alterara las hiladas más elevadas. Esta UE 3640 constituye, en realidad, un doble muro (Fig. 14): dispuesto apoyado sobre la cara norte de los cimientos de UE 149 (en dirección al muro 260, con el que no llega a conectar), se construye en primer lugar el situado al este (UE 3640a) y, posteriormente, se le adosa por el oeste otro similar (UE $3640 \mathrm{~b}$ ). Sus cotas más altas son: 
para el muro 3640a, 985,49 m en su extremo sur y 985,158 en su extremo norte, y para el muro $3640 \mathrm{~b}, 985,236 \mathrm{~m}$ en su extremo meridional y 985,414 en el septentrional.

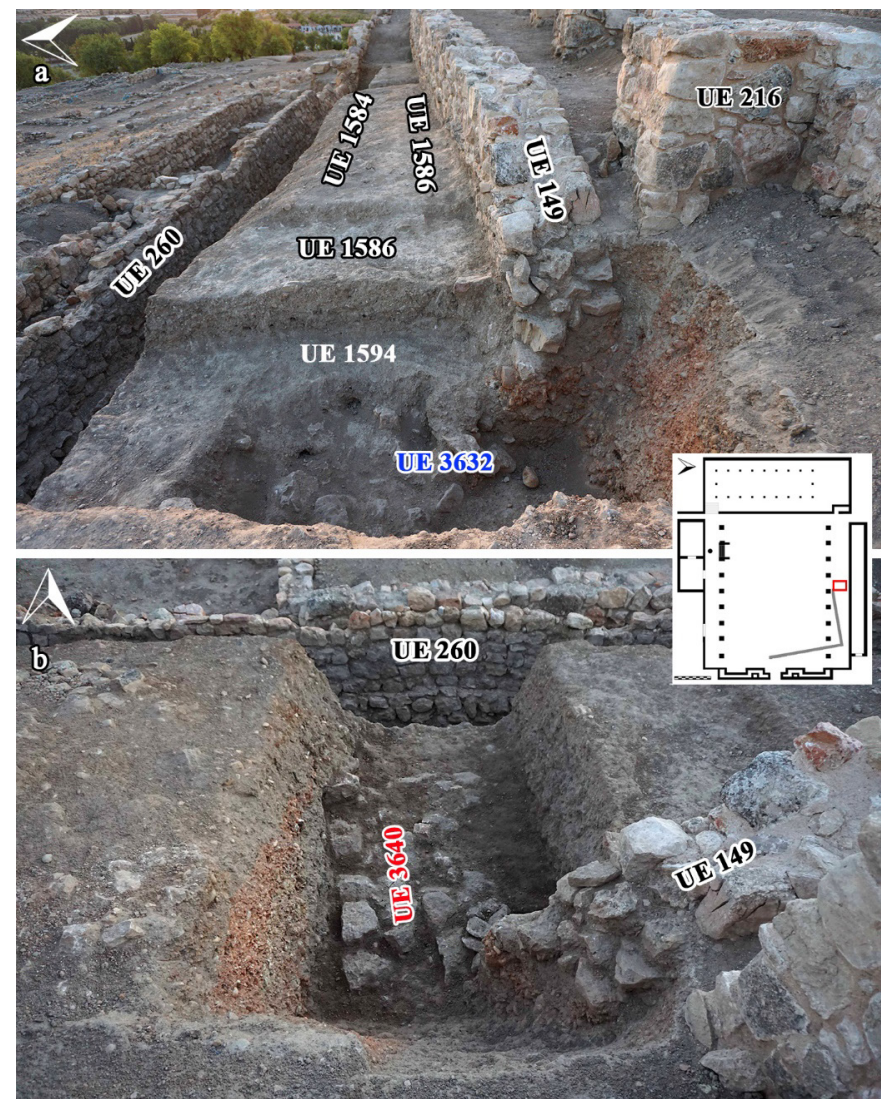

Figura 13. a. Aparición de la UE 3632 en el control efectuado en el extremo oeste del muro UE 149;

b. aparición del muro UE 3640 bajo la UE 3632

Al mismo tiempo, con el objetivo de ampliar el espacio para descubrir si el muro giraba en algún punto, se procedió a retocar los perfiles, especialmente los ubicados al oeste y al sur, en los que comenzaban a aparecer manchas rojizas. Efectivamente, mientras que por el lado este del muro (UE 3640a) se constata que todo el perfil (Fig. 14a) está ocupado por el mismo estrato (la UE 1594), en los flancos oeste y sur se produce la intrusión puntual (bajo 1594) de una capa de zahorra, muy compacta, que disminuye de espesor en 
dirección norte $(1,40 \mathrm{~m}$ en perfil sur, y 1,27 $\mathrm{m}$ de potencia máxima en el perfil oeste). Aunque este estrato es morfológicamente similar a la ya descrita UE 1583, le otorgamos un nuevo número, UE 3684 (Fig. 14b), para distinguirlo de aquella. De esta unidad se ha obtenido escaso material: algunos restos de fauna y de cerámica ibérica (ánfora, tosca, algún fragmento pintado). Por su parte, la UE 1594, junto al lado este del muro 3640, ha proporcionado igualmente cerámica ibérica (ánfora, pintada, gris, tosca), poca fauna, y un fragmento de «Campaniense A».

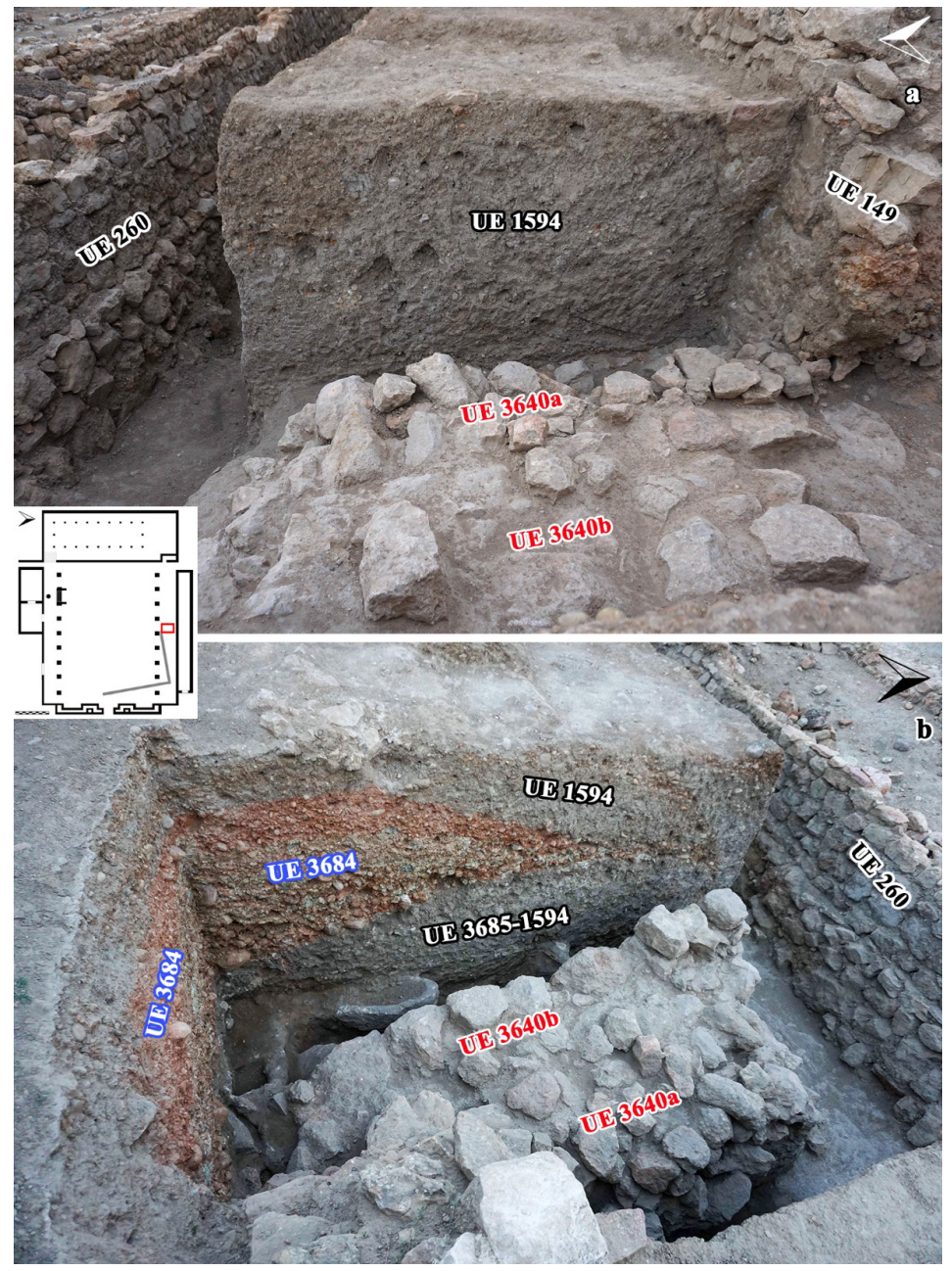

Figura 14. a. La UE 1594, en el perfil del lado Este del muro 3640a; b. unidades estratigráficas halladas en el perfil oeste del muro 3640b 


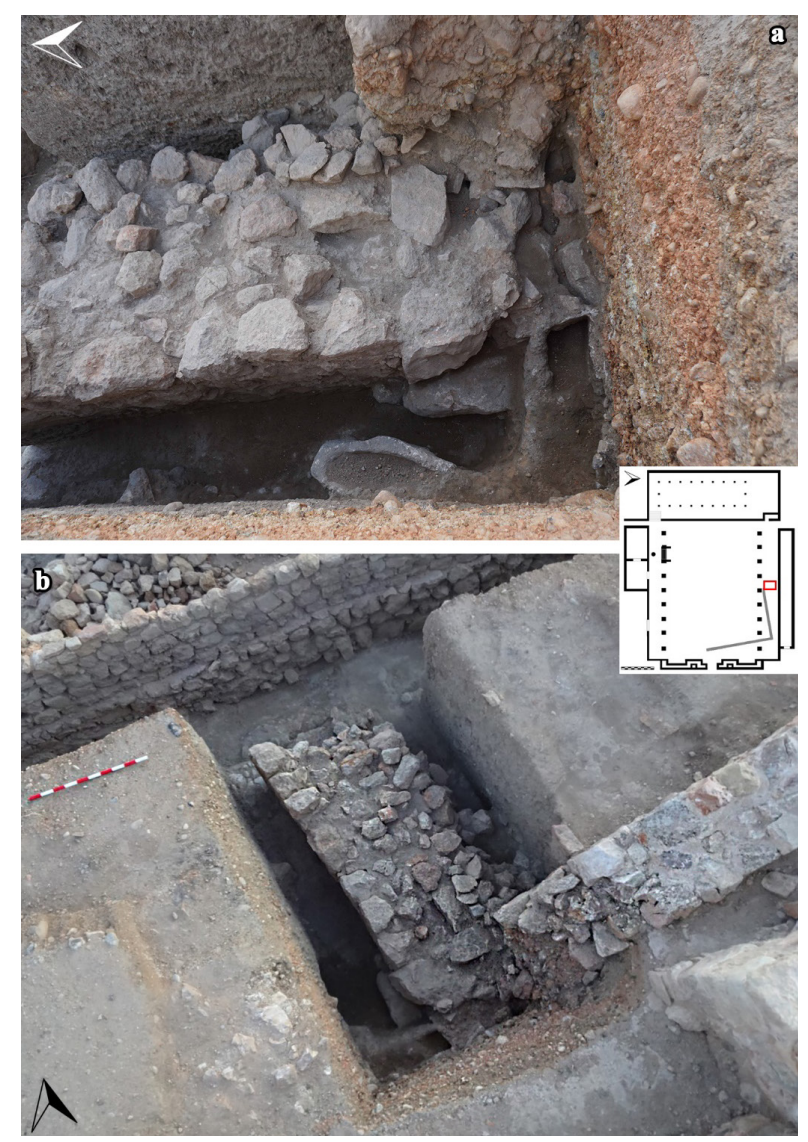

Figura 15. Finalización del muro 3640 en conexión con las piletas preexistentes

En el perfil oeste, junto a la UE 3684, en su extremo septentrional, y bajo ella en el centro, vuelve a aparecer la UE 1594 que, sin embargo, para evitar confusiones y porque se halla por debajo del nivel del enrase del muro 3640, denominamos UE 3685/1594 (Fig. 14b), aunque morfológicamente es idéntica a la UE 1594. De esta unidad estratigráfica se ha podido extraer cerámica ibérica fina y tosca, cerámica gris de cocción reductora, un fragmento de lucerna romana, escasa fauna y dos clavos de hierro, aunque el hallazgo más destacable es, sin duda, una pileta de piedra de forma trapezoidal (Fig. 14b-15a), de $64 \mathrm{~cm}$ de longitud, $43 \mathrm{~cm}$ en su lado ancho, $20 \mathrm{~cm}$ en el lado estrecho, y $21 \mathrm{~cm}$ de altura, provista de un reborde redondeado de 5 a $7 \mathrm{~cm}$ de grosor y $9 \mathrm{~cm}$ de profundidad. Con ella fueron 
exhumados 4 fragmentos de pared de cerámica ibérica sin decorar y otro pintado, 2 fragmentos borde de cerámica cocina, un fragmento de clavo de hierro, y un fragmento de borde de barniz negro de producción napolitana. Junto a la pileta de piedra, se hallaron indicios de otras dos, construidas con argamasa, justo en el perfil (Fig. 15a) y entre éste y los cimientos del muro UE 149.

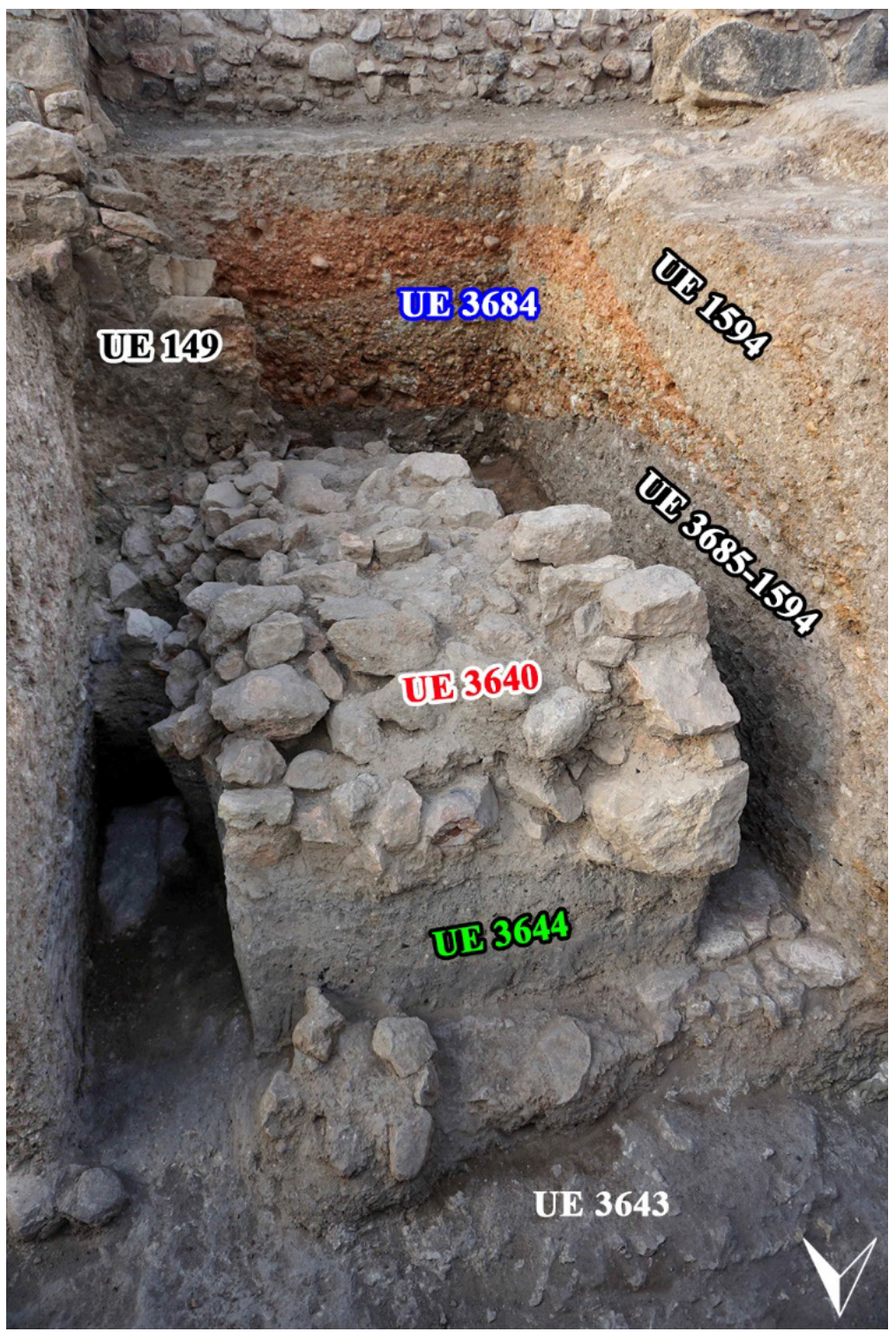

Figura 16. La UE 3644, bajo el muro 3640, y sobre la roca base UE 3643 
La estructura UE 3640 (Fig. 15b) alcanza una longitud de 2,90 m en dirección N-S, una anchura (E-W) de 1,90 m, y la altura máxima conservada (en su lado norte) es de 0,80 m. Como se puede observar bien en su extremo septentrional, el muro no está construido sobre la roca base, sino sobre una capa de tierra fina con intrusiones de carboncillos, la UE 3644, de 0,36 m de espesor (Fig. 16), que a su vez asienta sobre la roca base UE 3643, a una cota de $983,80 \mathrm{~m}$.

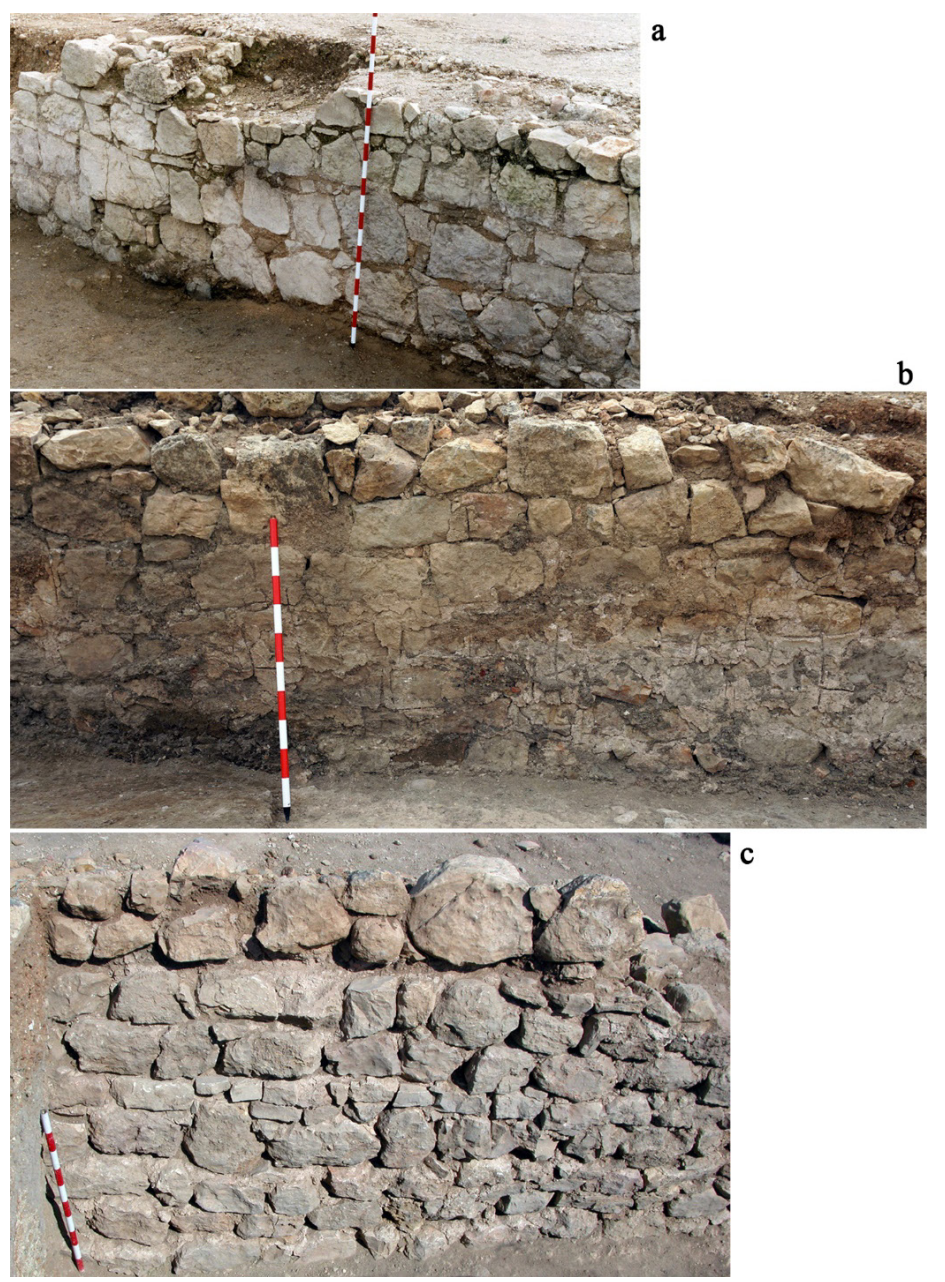

Figura 17. a. Parte del muro conservado de la fachada norte de la curia; b. cara interna (norte) del muro 260 (edificio del granero), con restos del revoque externo; c. cara externa (sur) del muro 260, originariamente enterrada 
Otro aspecto a tener en cuenta, para comprender la función del muro 149, es su fábrica. Si analizamos los aparejos de los muros de otros edificios del foro, podemos observar que la cara externa está formada por bloques de piedra más o menos escuadrados, y paramentos con tendencia al opus quadratum, como en el caso del muro perimetral norte de la curia (Fig. 17a), o en la cara septentrional del muro 260 (Fig. 17b), con argamasa en la trabazón y también en el revoque exterior, por tratarse de la zona interna del edificio. $\mathrm{E}$ incluso en su cara sur mantiene la misma estructura (Fig. 17c), aunque vaya a estar oculta cubierta por el relleno, y no contenga argamasa en el exterior. Sin embargo, la estructura UE 149 (Fig. 18) no tiene las características de un muro «caravista», está compuesto por mampuestos de tamaños muy diversos, y tampoco lleva argamasa, ni en el exterior ni en su trabazón: estaba oculto bajo el pavimento del pórtico norte, y su función era sujetar la presión ejercida por la pendiente de la ladera, que descargaba sobre el edificio del granero. Con 0,60 m de anchura y 17,60 m de longitud, conecta en su extremo este con el muro UE 230 en forma de L mayúscula, ubicándose el punto de conexión allí donde el relleno tiene mayor potencia (que afecta también a la fachada este del foro) y los cimientos del muro son más profundos, mientras que en su extremo oeste la roca base emerge a mayor altura y no necesita prolongarse en dirección a la basílica, interrumpiéndose ya en este punto.

En cuanto al muro UE 230, con el que el 149 forma ángulo recto en su extremo este, su función es la misma que la del 149: sujetar la presión del relleno de la pendiente, en su caso sobre la fachada este del foro. Pero en esta zona la roca base está mucho más alta, y el poco material exhumado con la tierra que rellena el espacio entre el muro 230 y los correspondientes a la fachada este ofrece, a pequeña escala, la misma información que la hallada en el ambiente 196. 


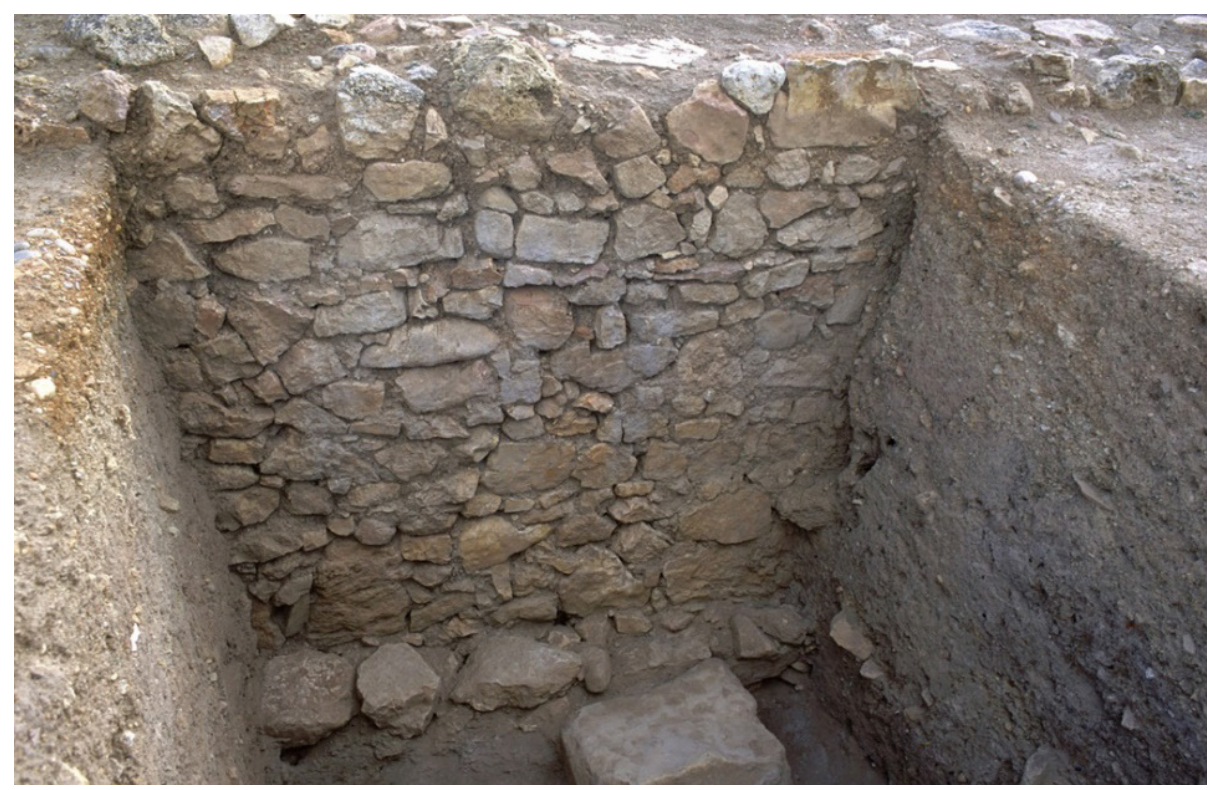

Figura 18. Detalle del muro UE 149, en su cara norte

\section{CONCLUSIÓN PRELIMINAR}

La excavación practicada en el ambiente 196, en paralelo al muro UE 260, con el objetivo de que se pudiera recolocar en posición vertical, además de indagar sobre los distintos aspectos de la construcción del horreum de la colonia romana y, en especial, su cronología, así como investigar sobre la función del muro 149, nos manifiesta claramente la existencia de un relleno, como se aprecia en las secciones de los distintos tramos (Fig. 19), depositado de una vez, entre los muros UE 149 y 260, con el material disponible, básicamente tierra gris en la práctica totalidad, con alguna dispersa y pequeña mancha de zahorra, casi ninguna piedra (reservada para los muros), y fragmentos de residuos cerámicos, de adobes ibéricos y tejas romanas. El material exhumado en estas unidades estratigráficas de relleno es ingente (supera el millar de fragmentos), en su inmensa mayoría cerámica ibérica (de todo tipo y tamaño: tanto fina como tosca, de almacenaje, cocina, servicio y consumo), seguida (a mucha distancia) de las importaciones itálicas de cronología re- 
publicana: básicamente ánforas vinarias, cerámica de barniz negro y de paredes finas.

Estamos, sin duda, ante uno de los grandes hallazgos de las últimas campañas, por la que refiere a la secuencia romana documentada en el sector 1B. Ambos muros (UE 149 y 260), dotados del mismo sistema de cimientos, se construyeron a la vez, en el momento de la edificación del foro, y, por lo tanto, el 149 no pertenece a una fase previa (como habíamos pensado inicialmente), sino que forma parte del diseño del foro colonial, con el objetivo de servir de sostén del gran relleno que se tiene que realizar en la parte norte de la plaza, para quitarle presión de la ladera al edificio del granero, el ambiente 10. Recordemos, al efecto, que el pavimento del ambiente 10 se encuentra $4 \mathrm{~m}$ por debajo del umbral de la curia, conservado in situ. La planificación era correcta, pues la potencia del relleno, en una pendiente tan pronunciada, requería de un muro de sostén. Cuando se produjo el terremoto en época altoimperial, el muro 149 resistió porque aguantaba menos presión al estar situado a una cota más alta, pero el 260 falló debido a su endeblez (Fig. 20): sus escasos $60 \mathrm{~cm}$ de anchura (frente a los $80 \mathrm{~cm}$ de su paralelo UE 134, el perimetral norte del edificio) no fueron suficientes para resistir la presión, en un lienzo de $35 \mathrm{~m}$ de $\mathrm{L}$, y no menos de $6 \mathrm{~m}$ de altura de vano interno, cimientos aparte.

Por último, el registro de datación más tardía de los niveles de relleno, especialmente los escasos fragmentos de terra sigillata hallados, corresponde a la época augustea, la fecha de fundación del foro de la colonia romana de Libisosa. Sobre esta fase, y su conexión con la forum, en función de los hallazgos en este sector, versarán futuros trabajos resultado, igualmente, de las últimas campañas de intervención. 


\section{REFERENCIAS BIBLIOGRÁFICAS}

ABASCAL PALAZÓN, J. M. (1990). Inscripciones romanas de la provincia de Albacete. Albacete: Instituto de Estudios Albacetenses «Don Juan Manuel».

ABASCAL PALAZÓN, J. M. y SANZ GAMO, R. (1993). Novedades de epigrafía romana en la provincia de Albacete. Al-Basit, 33, 13-36.

ALFÖLDY, G. (1975). Die römischen Inschriften von Tarraco. Berlin: De Gruyter.

ALFÖLDY, G. (1987). Römischen Städtewesen auf der neukastilischen Hochebene. Heidelberg: Carl Winter Universitätsverlag.

ANDREU PINTADO, J. (2008). Municipalización y vida municipal en las comunidades romanas de la Meseta Sur. En G. Carrasco Serrano (coord.), La romanización en el territorio de CastillaLa Mancha (pp. 225-260). Universidad de Castilla-La Mancha.

BELTRÁN LLORIS, F. (1999). Municipium C.R., 'Oppidum C.R.' y 'Oppidum latinum' en la $\mathrm{NH}$ de Plinio: una revisión del problema desde la perspectiva hispana. En J. González (ed.), Ciudades privilegiadas en el Occidente romano (247-267). Diputación de Sevilla-Universidad de Sevilla.

BLÁNQUEZ PÉREZ, J. J. (1990). La vía Heraclea y el camino de Aníbal.

Nuevas interpretaciones de su trazado en las tierras del interior. En Simposio sobre la red viaria en la Hispania romana (pp. 65-76). Institución Fernando el Católico.

CARRASCO SERRANO, G. (2009-2010). Contribución al análisis del proceso de romanización de la provincia de Albacete. Hispania Antiqua, 33-34, 157-167.

COARELLI, F. (1996). La romanización de Umbría. En J. M. Blázquez y J. Alvar (eds), La Romanización en Occidente (pp. 57-68). Madrid: Actas.

COARELLI, F. (2008). La romanizzazione della Sabina. En J. Uroz Sáez, F. Coarelli y J. M. Noguera (eds.), Iberia e Italia: modelos romanos de integración territorial (pp. 15-24). Tabularium. 
DE MIGUEL, M. P. y UROZ RODRÍGUEZ, H. (2017). Muerte violenta infantil durante las Guerras Sertorianas en el oppidum iberorromano de Libisosa (Lezuza, Albacete). En M. Diaz-Zorita, J. Escudero Carrillo, I. Lopez Flores, J. Lucena Romero, E. Mora Rosa y S. Robles Carrasco (eds.), Paleopatología y Bioarqueología, contextualizando el registro óseo. Actas del XIII Congreso Nacional de Paleopatología. (pp. 333-341). Asociación Profesional de Bioarqueología y Asociación Nacional de Paleopatología.

D’ORS, A. (1974). La condición jurídica del suelo en las provincias de Hispania. En I diritti locali nelle province romane con particolare riguardo alle condizioni giuridiche del suolo (pp. 253-268). Roma: Accademia Nazionale dei Lincei.

GALSTERER, H. (1971). Untersuchungen zum römischen Städtewesen auf der Iberischen Halbinsel. Berlin: De Gruyter.

GARCÍA Y BELLIDO, A. (1961-1962). Las colonias romanas de Valentia, Carthago Nova, Libisosa e Ilici. Aportaciones al estudio del proceso romanizador del sureste de la Península. En Homenaje al profesor Cayetano de Mergelina (pp. 367-372). Universidad de Murcia.

GONZÁLEZ ROMÁN, C. (1991): Las colonias romanas de la Hispania meridional en sus aspectos socio-jurídicos. En González Román (ed.), La Bética en su problemática histórica (pp. 87110). Universidad de Granada.

GONZÁLEZ ROMÁN, C. (1994). Ius italicum e immunitas en las colonias romanas de Hispania. En J. González (ed.), Roma y las provincias. Realidad administrativa e ideología imperial (pp. 131-145). Ediciones Clásicas.

HERNÁNDEZ CANCHADO, N. (2008). La cerámica de importación tardorrepublicana del barrio iberorromano de Libisosa: el departamento 79. Verdolay, 11, 143-178

LUZZATTO, G. I. (1974). Sul regime del suolo nelle province romane. En I diritti locali nelle province romane con particolare riguardo alle condizioni giuridiche del suolo (pp. 9-53). Accademia Nazionale dei Lincei. 
MAZZARINO, S. (1974). Ius Italicum e storiografia moderna. En I diritti locali nelle province romane con particolare riguardo alle condizioni giuridiche del suolo (pp. 357-372). Accademia Nazionale dei Lincei.

MUÑOZ OJEDA, F. J. (2004). Programa decorativo de un edificio singular en el Foro de Libisosa (Lezuza, Albacete). En S. F. Ramallo (ed.), La decoración arquitectónica en las ciudades romanas de occidente. Actas del Congreso Internacional (pp. 553-557). Universidad de Murcia.

ORTÍZ CÓRDOBA, J. (2019). Las colonias romanas de Hispania y los movimientos de población (siglos I-II d.C.). [Tesis Doctoral: Universidad de Granada].

POVEDA NAVARRO, A. M. (2002). Fora Hispania. La evidencia de Libisosa Forum Augustum (Lezuza, Albacete). Coninbriga, 41, 538. QUESADA SANZ, F. y UROZ RODRÍGUEZ, H. (2020). El armamento de época iberorromana de Libisosa (Lezuza, Albacete). Un conjunto excepcional. Gladius, 40, 19-72.

ROLDÁN HERVÁS, J. M. (1975). Itineraria Hispana. Fuentes antiguas para el estudio de las vías romanas de la Península Ibérica. Valladolid: Universidad de Valladolid y Universidad de Granada.

ROLDÁN HERVÁS, J. M. (2001). Conquista e integración administrativa. En J. M. Roldán Hervás y F. Wulff Alonso, Citerior y Ulterior. Las provincias romanas de Hispania en la era republicana (pp. 17-345). Istmo.

ROMERO DIAZ, M. A. y RUIZ GARCÍA, A. (1986). El endorreísmo en la provincia de Albacete: tipología y condicionamientos físicos. En I Reunión de Estudios regionales de Castilla La Mancha (pp. 202-255). Junta de Comunidades de Castilla-La Mancha.

SÁNCHEZ SÁNCHEZ, J. (1982). Geografía de Albacete. Factores de desarrollo económico de la provincia y su evolución reciente (2 tomos). Instituto de Estudios Albacetenses «Don Juan Manuel».

SANZ GAMO, R. (1989). Fuentes escritas sobre la Colonia Libisosa Forum Augustana. Información Cultural Albacete, 35, 312. 
SANZ GAMO, R. (2002-2003). La red viaria antigua, los topónimos de las fuentes clásicas, y las evidencias materiales en el eje esteoeste al paso por la provincia de Albacete. Boletín de la Asociación Española de Amigos de la Arqueología, 42, 345-354.

SILLIÈRES, P. (1982). Une grande route romaine menant à Carthagène: la voie Saltigi-Carthago Nova. Madrider Mitteilungen, 23, 247-257.

SILLIÈRES, P. (1999). Le Camino de Anibal, principal axe des communications entre l'Est et le Sud de l'Hispanie. En Centeno, R. M. S., García Bellido, M. P. y Mora G. (coords.), Rutas, ciudades y moneda en Hispania (Actas del II Encuentro Peninsular de Numismática Antigua, Porto, 1997), Anejos de AEspA XX (pp. 239-250). CSIC.

SORIA COMBADIERA, L. (2002). La estructuración del territorio albacetense durante el ibérico pleno (ss. VIII a.C.). Los grandes asentamientos y su distribución en el espacio. En II Congreso de Historia de Albacete. Volumen I: Arqueología y Prehistoria (pp. 137-144). Instituto de Estudios Albacetenses«Don Juan Manuel».

SORIA COMBADIERA, L. (2007). Los pueblos prerromanos del sureste de la Meseta Sur. En J. Pereira (ed.) Prehistoria y Protohistoria de la Meseta Sur (Castilla-La Mancha) (pp. 239-259). Almud, Ediciones de Castilla-La Mancha.

TOVAR, A. (1989). Iberische Landeskunde II. Las tribus y las ciudades de la antigua Hispania. Tomo 3, Tarraconensis, Baden-Baden: Verlag Valentin Koerner.

UROZ RODRÍGUEZ, H. (e. p.). Libisosa. Historia congelada. Instituto de Estudios Albacetenses. «Don Juan Manuel»

UROZ RODRÍGUEZ, H. (2020a). Libisosa: un «tesoro» para la investigación de Iberia e Hispania. En Carretero, A. y Papí, C. (coords.), Actualidad de la investigación arqueológica en España I (pp. 29-44). Madrid: Ministerio de Cultura y DeporteMuseo Arqueológico Nacional. 
UROZ RODRÍGUEZ, H. (2020b). Textile production and aristocracy in the Ibero-Roman oppidum of Libisosa (Lezuza, Albacete, Spain). En M. Bustamante-Álvarez, E. H. Sánchez López y J. Jiménez Ávila (eds.), Purpureae Vestes VII. Redefining textile handcraft. Structures, tools and production processes (67-78). Granada: Universidad de Granada.

UROZ RODRÍGUEZ, H. (2018): Más que objetos rituales: un nuevo conjunto de vasos plásticos ibéricos. Saguntum, 50, 129-163. UROZ RODRÍGUEZ, H. (2015). La vajilla de bronce romana tardorrepublicana de Libisosa. Madrider Mitteilungen, 56, 168-210.

UROZ RODRÍGUEZ, H. (2013). Héroes, guerreros, caballeros, oligarcas: tres nuevos vasos singulares ibéricos procedentes de Libisosa. Archivo Español de Arqueología, 86, 51-73.

UROZ RODRÍGUEZ, H. (2012). Prácticas rituales, iconografía vascular y cultura material en Libisosa (Lezuza, Albacete). Nuevas aportaciones al Ibérico Final del Sudeste. Universidad de Alicante.

UROZ RODRÍGUEZ, H. y ARÉVALO GONZÁLEZ, A. (2020). Tres conjuntos monetales de la destrucción del oppidum iberorromano de Libisosa (Lezuza, Albacete). Zephyrus, 86, 87-114.

UROZ RODRÍGUEZ, H., RIBERA I LACOMBA, A. y HERNÁNDEZ CANCHADO, N. (2020). Closed contexts in the destruction of the Iberian oppidum of Libisosa (Lezuza, Albacete-Spain) during the Sertorian War: import pottery. En I. Kamenjarin y M. Ugarković (eds.), Exploring the Neighborhood: the Role of Ceramics in Understanding Place in the Hellenistic World (pp. 105-117). Wien: Phoibos Verlag.

UROZ RODRÍGUEZ, H. y UROZ SÁEZ, J. (2016). Imagen divina, vaso ritual, mito aristocrático. La diosa y el príncipe ibero de Libisosa. En V. Gasparini (ed.), Vestigia. Miscellanea di studi storico-religiosi in onore di Filippo Coarelli nel suo $80^{\circ}$ anniversario (pp. 281-294). Franz Steiner Verlag.

UROZ RODRÍGUEZ, H. y UROZ SÁEZ, J. (2014). La Libisosa iberorromana. Un contexto cerrado de -y por las guerras sertorianas. 
En Sala, F. y Moratalla, J. (eds.), Las guerras civiles romanas en Hispania. Una revisión histórica desde la Contestania (pp. 199-215). Diputación Provincial de Alicante-Universidad de Alicante.

UROZ RODRÍGUEZ, H. y VELAZA, J. (2020). Una inscripción latina sobre ánfora ibérica de la Libisosa iberorromana. Pyrenae, 51.1, 73-84.

UROZ RODRÍGUEZ, H. y VELAZA, J. (2019a) Epigrafía ibérica de Libisosa. Palaeohispanica, 19, 211-228.

UROZ RODRÍGUEZ, H. y VELAZA, J. (2019b). Un fragmento de tabula de bronce procedente de la Colonia Libisosa Foroaugustana. Zeitschrift für Papyrologie und Epigraphik, 211, 310-312.

UROZ SÁEZ, J. (2012). La colonia romana de Libisosa y sus precedentes. En Carrasco, G. (coord.), La ciudad romana en Castilla-La Mancha (pp. 87-130). Universidad de Castilla-La Mancha.

UROZ SÁEZ, J. y MÁRQUEZ VILLORA, J. C. (2002). La puerta norte de Libisosa y su contexto arqueológico. En II Congreso de Historia de Albacete. Volumen I: Arqueología y Prehistoria (pp. 239244). Instituto de Estudios Albacetenses «Don Juan Manuel». UROZ SÁEZ, J., MOLINA VIDAL, J., POVEDA NAVARRO, A. M., y MÁRQUEZ VILLORA, J. C. (2004). Aproximación al conjunto arqueológico y monumental de Libisosa (Cerro del Castillo, Lezuza, Albacete). En Investigaciones Arqueológicas en Castilla-La Mancha (1996-2002) (pp. 181-191). Junta de Comunidades de Castilla-La Mancha.

UROZ SÁEZ, J., MOLINA VIDAL, J., y POVEDA NAVARRO, A. M. (2002). El foro de Libisosa. Datos preliminares de una investigación en curso. En II Congreso de Historia de Albacete. Volumen I: Arqueología y Prehistoria (pp. 245-251). Instituto de Estudios Albacetenses «Don Juan Manuel».

UROZ SÁEZ, J. y POVEDA, A. M. (2008). Modelos romanos de integración territorial en el sur de Hispania Citerior. En J. Uroz Sáez, F. Coarelli y J. M. Noguera (eds.), Iberia e Italia: modelos romanos de integración territorial (pp. 143-168). Tabularium. 
UROZ SÁEZ, J., POVEDA NAVARRO, A. M. y MÁRQUEZ VILLORA, J. C. (2006). La puerta norte de Libisosa: cronología y arquitectura. En Schattner, Th. G. y Valdés, F. (eds.), Puertas de ciudades. Tipo arquitectónico y forma artística (pp. 173-184). Philipp von Zabern-Diputación Provincial de Toledo.

UROZ SÁEZ, J., POVEDA NAVARRO, A. M. y MÁRQUEZ VILLORA, J. C. (2003) [2010]. Libisosa. La transformación de un oppidum en colonia romana. En A. M. Poveda y J. Uroz Sáez (eds.), La Iberia de los oppida ante su romanización. Homenaje a E. A. Llobregat Conesa (pp. 221-252). Museo Arqueológico Municipal de Elda.

UROZ SÁEZ, J., POVEDA NAVARRO, A. M., MUÑOZ OJEDA, F. J. y UROZ RODRÍGUEZ, H. (2007). El departamento 86: Una taberna del barrio industrial ibérico de Libisosa (Lezuza, Albacete). En J. M. Millán y C. Rodríguez (coords.), Arqueología de Castilla-La Mancha. Actas de las I Jornadas (pp. 143-170). Universidad de Castilla-La Mancha.

UROZ SÁEZ, J. y UROZ RODRÍGUEZ, H. (2016). La importancia de las vías de comunicación y Libisosa: ejército, comercio y romanización en su contexto arqueológico tardorrepublicano. En Carrasco, G. (coord.), Vías de comunicación romanas en Castilla-La Mancha (pp. 151-176). Universidad de Castilla-La Mancha. 